\title{
The UMIST database for astrochemistry $2012^{\star}$
}

\author{
D. McElroy ${ }^{1}$, C. Walsh ${ }^{1}$, A. J. Markwick ${ }^{2}$, M. A. Cordiner ${ }^{3,4}$, K. Smith ${ }^{1}$, and T. J. Millar ${ }^{1}$ \\ 1 Astrophysics Research Centre, School of Mathematics and Physics, Queen's University Belfast, Belfast BT7 1NN, UK \\ e-mail: dmcelroy03@qub.ac.uk \\ 2 Jodrell Bank Centre for Astrophysics, School of Physics and Astronomy, University of Manchester, Manchester M13 9PL, UK \\ 3 Astrochemistry Laboratory and the Goddard Center for Astrobiology, Mailstop 691, NASA Goddard Space Flight Center, \\ 8800 Greenbelt Road, Greenbelt, MD 20770, USA \\ ${ }^{4}$ Institute for Astrophysics and Computational Sciences, The Catholic University of America, Washington, DC 20064, USA
}

Received 28 September 2012 / Accepted 20 December 2012

\section{ABSTRACT}

\begin{abstract}
We present the fifth release of the UMIST Database for Astrochemistry (UDfA). The new reaction network contains 6173 gas-phase reactions, involving 467 species, 47 of which are new to this release. We have updated rate coefficients across all reaction types. We have included 1171 new anion reactions and updated and reviewed all photorates. In addition to the usual reaction network, we also now include, for download, state-specific deuterated rate coefficients, deuterium exchange reactions and a list of surface binding energies for many neutral species. Where possible, we have referenced the original source of all new and existing data. We have tested the main reaction network using a dark cloud model and a carbon-rich circumstellar envelope model. We present and briefly discuss the results of these models.
\end{abstract}

Key words. astrochemistry - molecular data - molecular processes - ISM: molecules - circumstellar matter

\section{Introduction}

Chemical models are an important tool in helping us understand various physical and chemical processes in space. The need for accurate models of chemical evolution of astrophysical environments is of ever-increasing importance as a new generation of ground-based and space-borne facilities opens up spectroscopic windows at high spatial and spectral resolution. The concurrent development of improved receivers and laboratory spectroscopy has led to the identification of more than 150 molecular species (ignoring isotopologues) and to the realisation that a full understanding of the physics and chemistry in molecular sources requires a detailed understanding of chemical kinetics and, in particular, reaction rate coefficients over a wide range of temperatures: from $10 \mathrm{~K}$ or less in pre-stellar cores, to several hundred Kelvin in hot molecular cores, to several thousand Kelvin in post-shock gas.

Although it has been widely recognised over the past decade that grain-surface chemistry can play a significant role in molecular synthesis, the many uncertainties associated with this has prevented the development of accurate quantitative models for surface chemistry. Thus, we do not attempt to include surface chemistry, and focus on describing gas-phase chemistry as accurately as possible.

In this paper, we present the fifth release of the UMIST Database for Astrochemistry, RATE12 (previous releases: RATE91 - Millar et al. 1991; RATE95 - Millar et al. 1997a; RATE99 - Le Teuff et al. 2000; RATE06 - Woodall et al. 2007). We have undertaken a major revision of the database. The gasphase chemistry is now described by 6173 reactions among 467 species, of which, 47 of these are new additions, composed

* All codes, along with reaction networks and data files, are accessible at http: //www . udfa.net. of 13 elements. We have a new website ${ }^{1}$ from which the reaction network and associated data and codes can be downloaded. We also include state-specific rate coefficients for deuterium fractionation of $\mathrm{H}_{3}^{+}$, a complete, singly-deuterated version of RATE12 and surface binding energies of neutral species. We have made updates to data across all reaction types and, in particular, have sought out original references to the data, giving the DOI (Digital Object Identifier) code, where available.

We use the entire gas-phase reaction network to model the chemistry in two environments: a dark cloud and a carbon-rich circumstellar envelope (CSE) surrounding an AGB star. Our results show that the data is sufficiently comprehensive to use in a range of astrophysical environments without the need to omit specific reactions or indeed to include additional reactions. Other environments for which RATE12 can be used without modification, along with careful treatment of molecular hydrogen and $\mathrm{CO}$ self shielding, are photodissociation regions (PDRs), hydrodynamic shock regions and diffuse clouds. Protoplanetary discs and hot molecular cores can be modelled with the addition of grain-surface chemistry.

In Sect. 2 we briefly describe the format of the data and in Sect. 3, we list the updates we have made. In Sect. 4 we outline some of the new features of RATE12, while in Sect. 5 we present the results of our model calculations which we also compare with observations of TMC- 1 and IRC +10216 .

\section{Species and related data}

We present the interstellar chemistry of 467 species, including 268 cations, 28 anions and 171 neutral species, in the form of the RATE12 reaction network, which is available electronically as a colon-separated file. The format of each line is explained

1 http://www.udfa.net 
Table 1. Format of the colon-separated reaction network file.

\begin{tabular}{|c|c|c|c|}
\hline Field Heading & Description & \multicolumn{2}{|c|}{ Comments } \\
\hline reaction no. & Reaction number & & \\
\hline type & Reaction type code & \multicolumn{2}{|c|}{ See Table 2 for codes } \\
\hline $\mathrm{RX}$ & Reactants & \multicolumn{2}{|c|}{$\begin{array}{l}\text { Either a chemical species or one } \\
\text { of: PHOTON, CRP, CRPHOT, e- }\end{array}$} \\
\hline $\mathrm{PX}$ & Reaction products & \multicolumn{2}{|c|}{ Either a chemical species or e- } \\
\hline $\mathrm{NE}$ & $\begin{array}{l}\text { Number of fitted } \\
\text { temperature ranges }\end{array}$ & \multicolumn{2}{|l|}{ See text } \\
\hline$\alpha, \beta$, and $\gamma$ & $\begin{array}{l}\text { Parameters used to calculate } \\
\text { the rate coefficient }\end{array}$ & \multicolumn{2}{|c|}{ See Sect. 2.1} \\
\hline $\mathrm{T}_{l} / \mathrm{T}_{u}$ & Lower/upper temperature & \multicolumn{2}{|c|}{$\begin{array}{l}\text { The lower/upper bound at which } \\
\text { the measured or calculated data } \\
\text { has been fitted }\end{array}$} \\
\hline ST & Source type & $\begin{array}{cc}\text { One of: } \\
\text { E } & - \\
\mathrm{M} & - \\
\mathrm{C} & - \\
\mathrm{L} & - \\
\end{array}$ & $\begin{array}{l}\text { Estimated } \\
\text { Measured } \\
\text { Calculated } \\
\text { A combination of a } \\
\text { number of experimental } \\
\text { values from the Literature }\end{array}$ \\
\hline $\mathrm{ACC}$ & Accuracy & $\begin{array}{cc}\text { Codes rep } \\
\text { A } & - \\
\text { B } & - \\
\text { C } & - \\
\text { D } & - \\
& \\
\text { E } & -\end{array}$ & $\begin{array}{l}\text { resenting an error of: } \\
<25 \% \\
<50 \% \\
\text { within a factor of } 2 \\
\text { within an order of } \\
\text { magnitude } \\
\text { highly uncertain }\end{array}$ \\
\hline REF & Reference & \multicolumn{2}{|c|}{ DOI or other, see text } \\
\hline
\end{tabular}

Table 2. Code, reaction type, and the number of each reaction type in RATE12.

\begin{tabular}{llc}
\hline \hline Code & Reaction type & Count \\
\hline AD & Associative Detachment & 132 \\
CD & Collisional Dissociation & 14 \\
CE & Charge Exchange & 579 \\
CP & Cosmic-Ray Proton (CRP) & 11 \\
CR & Cosmic-Ray Photon (CRPHOT) & 249 \\
DR & Dissociative Recombination & 531 \\
IN & Ion-Neutral & 2589 \\
MN & Mutual Neutralisation & 981 \\
NN & Neutral-Neutral & 619 \\
PH & Photoprocess & 336 \\
RA & Radiative Association & 92 \\
REA & Radiative Electron Attachment & 24 \\
RR & Radiative Recombination & 16 \\
\hline
\end{tabular}

in Table 1. Where available, Digital object identifiers (DOI) are used for the reference codes (REF). In cases where a DOI has not been found or does not exist, we adopt the RATE06 referencing method allocating a 4 digit code to each source. The reaction type codes are listed in Table 2.

For reactions where it has not been possible to define a single formula to fit the available data, the "NE" field gives the number of different temperature ranges for which we supply a different formula fitting the data. Care has been taken not to have any discontinuities in the rate coefficient between temperature ranges. Thus, if a particular rate coefficient is best fitted using two separate Arrhenius expressions for the temperature ranges 10-100 K and 100-1000 K, both expressions will give the same value at $100 \mathrm{~K}$. In order to evaluate the rate coefficient outside the given temperature range, we recommend that the user chooses the expression that is closest to the temperature of interest. While there is no guarantee that this will give the correct rate coefficient, we have taken care to ensure that, when evaluated at low temperatures $(<50 \mathrm{~K})$, no rate coefficient will become unphysically large. We discuss this issue further in Sect. 3.8.

\subsection{Calculation of the reaction rate coefficient using $\alpha, \beta$, and $\gamma$}

For two-body reactions the rate coefficient is given by the usual Arrhenius-type formula

$k=\alpha\left(\frac{T}{300}\right)^{\beta} \exp \left(\frac{-\gamma}{T}\right) \mathrm{cm}^{3} \mathrm{~s}^{-1}$,

where $T(\mathrm{~K})$ is the gas temperature. For direct cosmic-ray ionisation $($ type $=\mathrm{CP})$,

$k=\alpha \quad \mathrm{s}^{-1}$,

whereas for cosmic-ray-induced photoreactions (type $=\mathrm{CR}$ ),

$k=\alpha\left(\frac{T}{300}\right)^{\beta} \frac{\gamma}{1-\omega} \mathrm{s}^{-1}$,

where $\alpha$ is the cosmic-ray ionisation rate, $\gamma$ is the efficiency of the cosmic-ray ionisation event as defined in Eq. (8) of 
Gredel et al. (1989), and $\omega$ is the dust-grain albedo in the far ultraviolet (typically $0.4-0.6$ at $150 \mathrm{~nm}$ ). The cosmic-ray ionisation rates listed here are normalised to a total rate for electron production from cosmic-ray ionisation (primarily from $\mathrm{H}_{2}$ and $\mathrm{He}$ in dark clouds) of $\zeta_{0}=1.36 \times 10^{-17} \mathrm{~s}^{-1}$. Rates for both direct cosmic-ray ionisation and cosmic-ray-induced photoreactions can be scaled to other choices of the ionisation rate, $\zeta$, by multiplying the appropriate rate coefficients by $\zeta / \zeta_{0}$. For interstellar photoreactions (type $=\mathrm{PH}$ ), the rate coefficient is parameterised as,

$k=\alpha \exp \left(-\gamma A_{V}\right) \mathrm{s}^{-1}$,

where $\alpha$ represents the rate coefficient in the unshielded interstellar ultraviolet radiation field, $A_{\mathrm{V}}$ is the dust extinction at visible wavelengths and $\gamma$ is the parameter used to take into account the increased dust extinction at ultraviolet wavelengths.

\section{Updates since RATE06}

\subsection{Anion reactions}

In 2006, $\mathrm{C}_{6} \mathrm{H}^{-}$was discovered in the Taurus Molecular Cloud 1 (TMC-1) by McCarthy et al. (2006). Since then, it and other anions have been detected in a variety of sources (Brünken et al. 2007; Remijan et al. 2007; Sakai et al. 2010b; Cordiner et al. 2011). RATE12 includes 22 new anions, which are involved in 1280 reactions. The anion reaction network comes from Walsh et al. (2009) with rate coefficients updated to include more recent laboratory measurements.

Anions are formed primarily via radiative electron attachment,

$\mathrm{X}+e^{-} \rightarrow \mathrm{X}^{-}+\mathrm{h} v$,

and destruction mechanisms include mutual neutralization with abundant cations, photodetachment reactions and reactions with atoms: $\mathrm{H}, \mathrm{C}, \mathrm{O}$ and $\mathrm{N}$. Of the new anion reactions, 950 are "mutual neutralisation" reactions $\left(\mathrm{A}^{-}+\mathrm{B}^{+} \rightarrow \mathrm{A}+\mathrm{B}\right)$. This new reaction type, labelled "MN", replaces the RATE06 ion-molecule and ion-ion neutralisations reaction types (IM and II). We have included reactions of anions with the 20 most abundant cations in a dark cloud chemical model, along with the top 10 most abundant cations in the CSEs surrounding both an oxygen-rich and a carbon-rich AGB star. These reactions are all assumed to have the same rate coefficient, $k=7.51 \times 10^{-8}(T / 300)^{-0.5} \mathrm{~cm}^{3} \mathrm{~s}^{-1}$, as included in the model of Walsh et al. (2009). The products are obtained, where appropriate, by simple electron transfer. For cations with no direct neutral equivalent e.g., $\mathrm{H}_{3}^{+}$, we assume the neutralisation of the cation results in the same products as its dissociative recombination e.g. $\mathrm{C}_{6} \mathrm{H}^{-}+\mathrm{H}_{3}^{+} \rightarrow \mathrm{C}_{6} \mathrm{H}+\mathrm{H}_{2}+\mathrm{H}$.

\subsection{Dissociative recombination reactions}

Since the release of RATE06, many new dissociative recombination (DR) rate coefficients have been accurately measured, along with branching ratios, at the CRYRING storage ring experiment in Stockholm. In RATE12, we include new DR data for 18 species, resulting in the addition of 58 new reactions. This brings the total DR product channels to 532 (compared with 486 in RATE06), 146 of these are measured.

\subsection{Neutral-neutral reactions}

There are 74 new or updated neutral-neutral reactions in RATE12 which have been measured in the laboratory. These include rate coefficient measurements down to $24 \mathrm{~K}$ using the CRESU (Cinitique de Reaction en Ecoulement Supersonique Uniforme or Reaction Kinetics in Uniform Supersonic Flow) method, and measurements of the reactions of many hydrocarbons (e.g. Carty et al. 2001; Canosa et al. 2007; Loison \& Bergeat 2009; Berteloite et al. 2010).

\subsection{Cation-neutral reactions}

There are 174 new, and 30 updated, ion-neutral (IN) reactions in RATE12. The majority of the new cation-neutral reactions include neutral species new to RATE12. In RATE06 we included a separate "dipole-enhanced" reaction network, which enhanced rate coefficients at low temperatures in cases where the neutral species has a large, permanent dipole moment. Such enhancements, due to "dipole locking" effects (Troe 1987; Herbst \& Leung 1986), result in rate coefficients which have a $T^{-1 / 2}$ dependence at low temperatures. In our reaction file we included this power-law behaviour in all reactions for which (i) the neutral has a dipole moment in excess of 0.9 Debye; (ii) the reaction does not already have a temperature dependence; and (iii) the reaction does not have a measured rate coefficient at low temperatures. Woon \& Herbst (2009) present an alternative approach, based on the $\mathrm{Su}-\mathrm{Chesnavich}$ expression $\mathrm{Su}$ \& Chesnavich 1982). In RATE12, we offer only the "dipoleenhanced" reaction network which has been shown to give a much better fit to observations at low temperatures while not significantly influencing results at high temperature ( $\lesssim 1000 \mathrm{~K})$.

\subsection{Radiative association}

There are just 17 updated or new radiative association (RA) rate coefficients in RATE12. Although these are not many in number, several important reactions have been revisited, measured or calculated. These include reactions of $\mathrm{C}_{2} \mathrm{H}_{2}^{+}, \mathrm{CH}_{2}^{+}$and $\mathrm{C}^{+}$with molecular hydrodgen and the radiative association of $\mathrm{H}$ and $\mathrm{H}^{+}$.

\subsection{Cosmic-ray-induced photoreactions}

RATE12 includes at least one cosmic-ray photoreaction rate coefficient for all neutral and anionic species in the reaction network.

\subsection{Photoprocesses}

Since the last release of the database, many new photodissociation and photoionisation rates, along with depth-dependent rates, have been calculated (van Hemert \& van Dishoeck 2008). These rates along with some corrections and unpublished data, have been incorporated into the database (van Dishoeck 2011, priv. comm.). We have also recalculated anion photorates using the Draine interstellar radiation field (Draine 1978), and the power law described in Millar et al. (2007). RATE12 now includes at least one photoprocess for every neutral species in the reaction network.

\subsection{Refits to problematic reaction rates}

In RATE06, there was a list of reaction ID's for which it was recommended that the rate coefficients be set to zero at $10 \mathrm{~K}$. This is because the best fit for the available data had a negative value for $\gamma$, which, in some cases, led to unrealistic divergent behaviour at low temperatures. Röllig (2011) addressed this problem and refitted many of the problematic reactions in RATE06. He fixed the 
value of the rate coefficient at $10 \mathrm{~K}$ to a particular value and used a fitting algorithm to find a new Arrhenius-type expression for the reaction. That paper also gave new fits for reactions which have discontinuities at certain temperatures, or temperature ranges in which no rate coefficient is defined in RATE06. He did this because, when using chemical models, it is often preferable to have a reaction rate that is continuous within the errors, than one that has discontinuities. In RATE12 we incorporate many of the changes suggested by Röllig (2011), and we use a similar method to fit some of our new reaction rate coefficients.

\subsection{HNCO isomers}

Three of the four isomers of isocyanic acid (HNCO) have been detected in space (Marcelino et al. 2008; Brünken et al. 2010). A comprehensive gas and grain reaction set was compiled and modelled by Quan et al. (2010). We have included all of the gasphase reactions from Quan et al. (2010) in RATE12.

\section{What's new in RATE12}

\subsection{Deuterium chemistry}

In order to accurately model deuterium chemistry, all D-bearing analogues of H-bearing species need to be included in a chemical model. This can increase the number of reactions by roughly an order of magnitude as well as increasing the number of ODEs to be solved. In order to reduce the number of reactions, specific rules can be adopted to limit the types of reaction that can occur (Roberts \& Millar 2000). In addition, branching ratios and rates can differ significantly from their $\mathrm{H}$ equivalent and are often unmeasured. For these reasons, we are providing a list of important deuterium exchange reactions as well as a singly-deuterated version of RATE12 for download from our website.

Flower et al. (2004) have shown that the $\mathrm{H}_{2}$ ortho/para ratio has a strong influence on the deuterium fractionation in interstellar clouds. We also include, for download, a set of state-specific deuterated reactions involving isotopologues of $\mathrm{H}_{2}, \mathrm{H}_{2}^{+}$, and $\mathrm{H}_{3}^{+}$, mostly taken from Flower et al. (2004), Walmsley et al. (2004) and Hugo et al. (2009).

\subsection{Reaction notes files}

We have recorded detailed sets of notes for each new and updated reaction, giving comments on possible fits and reasons for particular choices regarding rate coefficients. These are available on the website.

\subsection{Data source references}

Where possible, we have cited the original source of data for each reaction. Correct citing of the data is important, not only to gauge the accuracy or reliability of a particular reaction rate coefficient, but also to ensure the original authors are correctly cited in future publications. All new and updated reactions are referenced with a DOI, where available, which allows website users to link directly to the paper's webpage if they require further information on the data. We have also provided DOI codes, where available, for existing sources and located references for over 1200 reactions which were lacking source information in earlier versions of the database. In Appendix A, we list separately all original sources of laboratory and literature data.

\subsection{INCHI codes}

We have assigned all species in the database with an IUPAC International Chemical Identifiers (InChI). The InChI is a layered, variable length ASCII identifier which allows each species to be uniquely described. The Standard versions of InChI and InChIKey have been generated, where possible, for species in RATE12 and many of these have been cross-referenced against InChI data in other databases ${ }^{2}$.

\subsection{VAMDC collaboration}

UDfA is a part of the VAMDC project. VAMDC, the Virtual Atomic and Molecular Data Centre, aims to build a reliable, open, flexible interface to existing atomic and molecular (A\&M) data hosted in various databases worldwide (Dubernet et al. 2010; Rixon et al. 2011). It will provide the wide community of both European and global users with access to a comprehensive, federated set of A\&M data and application resources ${ }^{3}$.

\subsection{Surface binding energies}

In order to model grain-surface chemistry accurately, many factors need to be taken into account; the grain-surface morphology, composition, layering and grain size all effect how the chemistry progresses (Cuppen \& Herbst 2005). In addition, under certain conditions, normal rate equation methods for modelling surface chemistry are inadequate and stochastic approaches such as Monte-Carlo, modified rate-equation and master equation methods are needed to model grain-surface chemistry more accurately (Charnley 1998; Caselli et al. 1998; Biham et al. 2001).

Surface binding-energies can be used for determining thermal and cosmic-ray-induced desorption rates from interstellar dust-grains and also for estimating the diffusion barriers between grain surface sites (Hasegawa et al. 1992). In RATE12, we have included a list of surface binding energies for 206 species. The binding energies in the list are a mixture of theoretical work, estimates and measurements (Hasegawa et al. 1992; Hasegawa \& Herbst 1993; Tielens \& Allamandola 1987; Allen \& Robinson 1977; Garrod \& Herbst 2006). Whittet et al. (1998) observed that water ice is the main constituent of interstellar dust-grain ice mantles and so, where possible, we have listed the values measured in water ice. We include recent measurements from Collings et al. (2004), Öberg et al. (2009b), Öberg et al. (2009c) and Edridge (2010).

\subsection{New website}

Our website ${ }^{4}$ has been significantly updated for this release of the database. In addition to being able to download the entire RATE12 reaction network, users can also now download the control models presented here, together with instructions on how to run and modify them. A singly-deuterated version of the whole reaction network, a state-specific deuterium chemistry and a list of surface binding energies are also available to download.

Comprehensive searching of the database by chemical species is, of course, possible. In addition, we have integrated

\footnotetext{
2 For more information about InChIs see http://www. inchi-trust.org

3 For more information about VAMDC and its associated standards, see http: //www . vamdc. eu

4 http://www.udfa.net
} 
content previously available ${ }^{5}$. This means that the entry for each species contains considerably more information than just those of reactions involving it. We now also present the control model data for both the dark cloud and circumstellar envelope models and the user can also explore the effects of switching on or off specific reactions. In addition, it is now possible to view results from a sensitivity analysis on a species by species basis. This analysis follows the method of Wakelam et al. (2010b), where many models are run with the reaction rate coefficients varied within the quoted errors using a log-normal distribution. The analysis provides information on the variation of the mean value of the fractional abundance of each species with time, and the first and second standard deviations away from the mean, for every species in the database and for both control models.

For each reaction, as much information as possible is presented regarding the evolution of rate coefficient data between previous releases of UDfA and the this one. In most cases where a rate coefficient has changed between RATE06 and RATE12, there is now an explanatory note. In the future, changes will not be made without these notes, and the version of the database at the time of publication will remain available, even if it is not the current one.

Finally, users of the website can comment directly on any species or reaction, for example, to discuss the values we have adopted or to alert us and the community to new laboratory or theoretical data.

\section{Results}

In this section, we use the complete RATE12 reaction network in two models: a dark cloud, and a circumstellar envelope (CSE) of a mass-losing, carbon-rich AGB star. Although we shall compare our results with observations towards two archetypical and well-studied objects, TMC-1 (CP) and IRC+10216, our purpose here is not to reproduce the observations in detail, but to check (i) whether our global rate file gives a reasonable first approximation to the chemistry in these objects and (ii) whether there are particular species for which our new gas-phase model dramatically fails to reproduce observations. The latter item will highlight particular species or reactions which require further investigation or whether additional chemical processes are required, e.g., grain-surface chemistry.

\subsection{Dark cloud model}

We model the gas-phase chemistry of a dark cloud by treating it as an homogeneous, isotropic cloud with constant physical parameters: $n\left(\mathrm{H}_{2}\right)=10^{4} \mathrm{~cm}^{-3}, T=10 \mathrm{~K}, A_{\mathrm{V}}=10 \mathrm{mag}$, a dust-grain albedo in the far ultraviolet of 0.6 and a cosmicray ionisation rate of $1.3 \times 10^{-17} \mathrm{~s}^{-1}$. No grain-surface chemistry is included in this model except the formation of $\mathrm{H}_{2}$ via the association of two $\mathrm{H}$ atoms. This occurs at a rate of $\left(5.2 \times 10^{-17}\right)(T / 300)^{0.5} n_{\mathrm{H}} n(\mathrm{H}) \mathrm{cm}^{-3} \mathrm{~s}^{-1}$ which assumes that all $\mathrm{H}$ atoms that stick to a grain surface will recombine to form $\mathrm{H}_{2}$. Our initial elemental abundances, which are listed in Table 3, are identical to those in Garrod et al. (2008), these are the low-metal abundances of Graedel et al. (1982), updated with more recent diffuse cloud values for $\mathrm{He}, \mathrm{C}^{+}, \mathrm{N}$ and $\mathrm{O}$.

\footnotetext{
5 See http://www.astrochemistry.net
}

Table 3. Initial abundances relative to total $\mathrm{H}$ nuclei, $n_{\mathrm{H}}$.

\begin{tabular}{lccc}
\hline \hline Species $i$ & $n_{i} / n_{\mathrm{H}}{ }^{1}$ & Species $i$ & $n_{i} / n_{\mathrm{H}}$ \\
\hline $\mathrm{H}_{2}$ & 0.5 & $\mathrm{Na}$ & $2.0(-09)$ \\
$\mathrm{H}$ & $5.0(-05)$ & $\mathrm{Mg}$ & $7.0(-09)$ \\
$\mathrm{He}$ & 0.09 & $\mathrm{Si}$ & $8.0(-09)$ \\
$\mathrm{C}$ & $1.4(-04)$ & $\mathrm{P}$ & $3.0(-09)$ \\
$\mathrm{N}$ & $7.5(-05)$ & $\mathrm{S}$ & $8.0(-08)$ \\
$\mathrm{O}$ & $3.2(-04)$ & $\mathrm{Cl}$ & $4.0(-09)$ \\
$\mathrm{F}$ & $2.0(-08)$ & $\mathrm{Fe}$ & $3.0(-09)$ \\
\hline
\end{tabular}

Notes. ${ }^{(1)} a(b)=a \times 10^{b}$.

\subsubsection{Model results}

Although we are not constructing a model of a particular dark cloud, it is instructive nonetheless, to compare a simple model with observations of TMC-1 (CP), the cyanopolyyne peak in the TMC-1 ridge, a dark cloud region in which over 60 molecules have been detected. In order to compare our model results with TMC-1 (CP) observed values, we used a simple method where we select the best-fit time as the time at which the most modelled abundances "match" those observed. We define a match for a particular species when its calculated abundance agrees within an order of magnitude of the observed value. This definition of a match, while simple, has the advantage of giving equal weight to all species. Thus, species which are known to have an incorrect or incomplete chemistry do not skew the agreement. For example, if we used the "distance" method of Wakelam et al. (2006), the calculation of the "best time" would be completely dominated by $\mathrm{CH}_{3} \mathrm{OH}$, whose modelled abundance is more than 3 orders of magnitude lower than its observed value at all times in the model. It is well known that gas-phase models do not reproduce the methanol abundances seen in dark clouds, so this method would not give a good estimate of how well the model fits observations.

As our model does not include grain-surface chemistry, we do not expect those species thought to form in, and on, grain mantles, such as methanol, to have an accurately modelled abundance. Our models are also clearly unphysical for times greater than about 1-2 million years since freeze out onto grain surfaces will dominate the evolution of the gas-phase abundances. Table 4 shows the observed and computed best-time abundances for 63 species at our "best-fit time" (defined above), $\sim 2 \times 10^{5}$ years, when 41 of 63 species have abundances falling within an order of magnitude of those observed. A further 14 species match at some time between $10^{4}$ and $10^{8}$ years. In the table, the species listed in bold font are those for which the modelled abundance never falls within an order of magnitude of the observed value. Some of these species, for example, methanol and acetaldehyde, are generally thought to be produced mainly through grain-surface processes. However, other species, for instance, $\mathrm{C}_{2}, \mathrm{C}_{2} \mathrm{H}$ and $\mathrm{C}_{4} \mathrm{H}$, are not thought to be influenced greatly by grain chemistry. The fact that these three species fall significantly below their observed values and the abundances calculated with RATE06, indicates that the updated RATE12 chemistry results in reduced abundances of $\mathrm{C}_{2}$-bearing species and some of the higher-order carbon chains, whose abundances depend strongly on the $\mathrm{C}_{2}$ chemistry.

One reaction which makes a significant difference to how well our results agree with observations, is $\mathrm{C}_{2} \mathrm{H}+\mathrm{O} \rightarrow \mathrm{CO}+$ $\mathrm{CH}$, one of the "key reactions" in the KIDA database (KInetic 


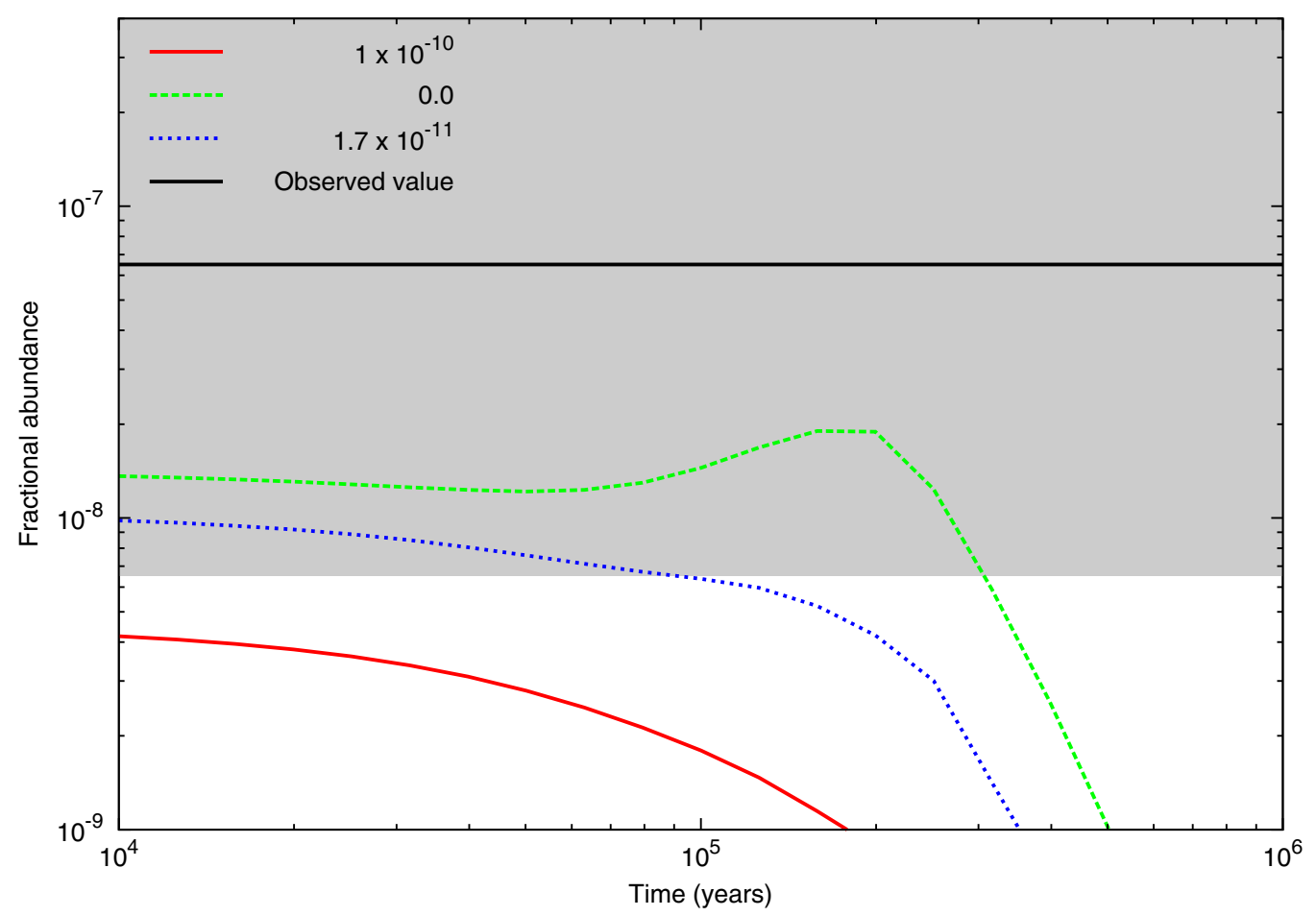

Fig. 1. Plot of $\mathrm{C}_{2} \mathrm{H}$ fractional abundance, relative to $\mathrm{H}_{2}$ abundance, as a function of time using different values of the rate coefficient for the reaction, $\mathrm{C}_{2} \mathrm{H}+\mathrm{O} \rightarrow \mathrm{CO}+\mathrm{CH}$. The shaded region corresponds to an order of magnitude error on the observed abundance in TMC-1 (CP).

Database for Astrochemistry ${ }^{6}$, Wakelam et al. 2012). RATE12 adopts the same high value for the rate coefficient, $10^{-10} \mathrm{~cm}^{3} \mathrm{~s}^{-1}$, as recommended in the KIDA datasheets; the RATE06 value for this reaction is $1.7 \times 10^{-11} \mathrm{~cm}^{3} \mathrm{~s}^{-1}$ at $10 \mathrm{~K}$, on the recommendation of Baulch et al. (1992), based on laboratory measurements at room temperature and higher. Subsequently, Baulch (2005) recommended a rate coefficient about an order of magnitude larger with a constant value over a wide temperature range, based on a single measurement at $600 \mathrm{~K}$. As it turns out, using the "old" lower value gives a better agreement with observations for a number of species such as $\mathrm{C}_{2} \mathrm{H}, \mathrm{C}_{4} \mathrm{H}, \mathrm{CH}_{3} \mathrm{CHCH}_{2}$ and $\mathrm{SO}_{2}$, while setting the rate coefficient to zero makes the agreement even better, this can be seen for $\mathrm{C}_{2} \mathrm{H}$ in Fig. 1. While one cannot accurately infer a rate coefficient from astrophysical data, this example highlights the importance of knowing rate coefficients accurately at low temperatures.

In order to see how RATE12 compares with the KIDA database, we ran a dark cloud model, using the reaction network "kida.uva.2011", with the same physical conditions and initial abundances as above. This reaction network is the most recent reaction network from the KIDA website for use in dense interstellar clouds.

As expected, the model results are largely similar to RATE12. Using the same criteria as above, we find that of the 62 modelled species that have been observed in TMC1 (CP), 38 agree at a "best fit" time of $2.5 \times 10^{5}$ years. In Table 5, we list those species for which we find either RATE12 only or kida.uva.2011 only agree with observations. Of the species for which RATE12 shows a better fit, those that stand out include acetaldehyde, propene and formic acid. The differences between the kida.uva.2011 and RATE12 results for acetaldehyde and formic acid can be explained by the newly measured dissociative recombination rate

\footnotetext{
6 http://kida.obs.u-bordeaux1.fr
}

coefficients for the reactions

$$
\begin{aligned}
\mathrm{CH}_{3} \mathrm{CHOH}^{+}+\mathrm{e}^{-} & \rightarrow \mathrm{CH}_{3} \mathrm{CHO}+\mathrm{H}, \quad \text { and } \\
\mathrm{HCOOH}_{2}^{+}+\mathrm{e}^{-} & \rightarrow \mathrm{HCOOH}+\mathrm{H} .
\end{aligned}
$$

These rate coefficients are larger than their previous values and are each the main formation mechanism for their respective products (Vigren et al. 2010a; Hamberg et al. 2010). Similarly, kida.uva.2011 is missing reactions that synthesise propene efficiently. In RATE12, propene formation is initiated by the dissociative recombination of $\mathrm{C}_{3} \mathrm{H}_{7}^{+}$as outlined in Herbst et al. (2010). One species that is highly underabundant in RATE12 is $\mathrm{C}_{2} \mathrm{~S}$, caused by the large rate coefficient of $1 \times 10^{-10} \mathrm{~cm}^{-3} \mathrm{~s}^{-1}$ for its destruction by atomic oxygen. This reaction has been deemed likely to proceed without a barrier by Loison et al. (2012), and is another example of how lack of low temperature data can have a large impact on calculated abundances.

The major difference between Rate 12 and Rate06 is the inclusion of anion reactions. Walsh et al. (2009) investigated the effect of anions on the chemistry in dark clouds. They used the RATE06 reaction network and added a set of carbon-chain anion reactions. They found that the addition of these anion reactions resulted in enhanced abundances of several families of carbon-chain molecules and better agreement with the observed values of cyanopolyyne molecules in TMC-1 (CP). Many of the same reactions and species are included in RATE12 and, as expected, the main differences between RATE06 and RATE12 are the same as those found by Walsh et al. (2009). Other differences not previously discussed are an improved agreement with abundances for both propyne and OCS. The former may be attributed to RATE12 having a more comprehensive treatment of allene $\left(\mathrm{CH}_{2} \mathrm{CCH}_{2}\right)$ and propyne $\left(\mathrm{CH}_{3} \mathrm{CCH}\right)$ than RATE06, with the latter due to the inclusion of the newly reviewed and updated OCS chemistry of Loison et al. (2012). 
D. McElroy et al.: The UMIST database for astrochemistry 2012

Table 4. Observed fractional abundances, relative to $\mathrm{H}_{2}$, in TMC-1 (CP) and corresponding modelled "best fit" values.

\begin{tabular}{|c|c|c|c|c|c|c|c|c|c|}
\hline Species & Observed & Calculated & Agree? & Ref. & Species & Observed & Calculated & Agree? & Ref \\
\hline $\mathbf{C}_{2}$ & $5.0(-08)^{1}$ & $3.0(-10)$ & & & $\mathbf{C}_{2} \mathbf{H}$ & $6.5(-08)$ & 1.1(-09) & & 5 \\
\hline $\mathrm{C}_{2} \mathrm{O}$ & $6.0(-11)$ & $1.4(-11)$ & $\mathrm{Y}$ & & $\mathrm{C}_{2} \mathrm{~S}$ & $3.4(-09)$ & $9.9(-13)$ & & 3 \\
\hline $1-\mathrm{C}_{3} \mathrm{H}$ & $8.0(-11)$ & $6.9(-10)$ & $\mathrm{Y}$ & 6 & $\mathrm{c}-\mathrm{C}_{3} \mathrm{H}_{2}$ & $1.1(-08)$ & $4.9(-09)$ & $\mathrm{Y}$ & \\
\hline $\mathrm{C}_{3} \mathrm{~N}$ & $6.0(-10)$ & $1.7(-10)$ & $\mathrm{Y}$ & & $\mathrm{C}_{3} \mathrm{~N}^{-}$ & $<7.0(-11)$ & $9.2(-13)$ & Y & \\
\hline $\mathrm{C}_{3} \mathrm{O}$ & $1.0(-10)$ & $1.4(-10)$ & $\mathrm{Y}$ & & $\mathrm{C}_{3} \mathrm{~S}$ & $1.0(-09)$ & $3.9(-10)$ & $\mathrm{Y}$ & \\
\hline $\mathbf{C}_{4} \mathbf{H}$ & $6.1(-08)$ & $2.1(-09)$ & & & $\mathrm{C}_{4} \mathrm{H}^{-}$ & $<2.3(-12)$ & $1.6(-11)$ & Y & \\
\hline $\mathrm{C}_{5} \mathrm{H}$ & $5.8(-10)$ & $1.4(-09)$ & $\mathrm{Y}$ & 2 & $\mathrm{C}_{5} \mathrm{~N}$ & $3.0(-11)$ & $8.1(-11)$ & Y & 12 \\
\hline $\mathrm{C}_{6} \mathrm{H}$ & $7.5(-10)$ & $1.7(-09)$ & $\mathrm{Y}$ & & $\mathrm{C}_{6} \mathrm{H}^{-}$ & $1.2(-11)$ & $4.2(-11)$ & $\mathrm{Y}$ & \\
\hline $\mathrm{C}_{7} \mathrm{H}$ & $1.5(-11)$ & $4.1(-10)$ & & 2 & $\mathrm{C}_{8} \mathrm{H}$ & $4.6(-11)$ & $2.4(-10)$ & $\mathrm{Y}$ & \\
\hline $\mathrm{C}_{8} \mathrm{H}^{-}$ & $2.1(-12)$ & $4.2(-12)$ & $\mathrm{Y}$ & & $\mathrm{CH}$ & $1.5(-08)$ & $2.8(-09)$ & Y & 4 \\
\hline $\mathrm{CH}_{2} \mathrm{CHCN}$ & $4.5(-09)$ & $1.8(-11)$ & & 8 & $\mathrm{CH}_{2} \mathrm{CN}$ & $5.0(-09)$ & $1.8(-10)$ & & \\
\hline $\mathrm{CH}_{2} \mathrm{CO}$ & $6.0(-10)$ & $4.4(-08)$ & & & $\mathrm{CH}_{2} \mathrm{NH}$ & $<3.6(-09)$ & $3.5(-10)$ & Y & 3 \\
\hline $\mathrm{CH}_{3} \mathrm{C}_{3} \mathrm{~N}$ & $4.5(-11)$ & $6.5(-10)$ & & 8 & $\mathrm{CH}_{3} \mathrm{C}_{4} \mathrm{H}$ & $1.8(-10)$ & $7.6(-13)$ & & 9 \\
\hline $\mathrm{CH}_{3} \mathrm{C}_{5} \mathrm{~N}$ & $7.4(-11)$ & $2.1(-11)$ & $\mathrm{Y}$ & 11 & $\mathbf{C H}_{3} \mathbf{C}_{6} \mathbf{H}$ & $3.1(-10)$ & $2.6(-13)$ & & 9 \\
\hline $\mathrm{CH}_{3} \mathrm{CCH}$ & $6.0(-09)$ & $5.6(-10)$ & & & $\mathrm{CH}_{3} \mathrm{CHCH}_{2}$ & $4.0(-09)$ & $1.1(-09)$ & $\mathrm{Y}$ & 13 \\
\hline $\mathrm{CH}_{3} \mathrm{CHO}$ & $6.0(-10)$ & $2.3(-10)$ & $\mathrm{Y}$ & & $\mathrm{CH}_{3} \mathrm{CN}$ & $6.0(-10)$ & $6.0(-09)$ & $\mathrm{Y}$ & \\
\hline $\mathrm{CH}_{3} \mathrm{OH}$ & $3.0(-09)$ & $9.4(-13)$ & & & $\mathrm{CN}$ & $5.0(-09)$ & $1.1(-08)$ & $\mathrm{Y}$ & \\
\hline $\mathrm{CO}$ & $8.0(-05)$ & $2.5(-04)$ & $\mathrm{Y}$ & & CS & $4.0(-09)$ & $7.6(-09)$ & Y & \\
\hline $\mathrm{H}_{2} \mathrm{CO}$ & $5.0(-08)$ & $5.7(-08)$ & $\mathrm{Y}$ & & $\mathrm{H}_{2} \mathrm{CS}$ & $7.0(-10)$ & $2.0(-09)$ & Y & \\
\hline $\mathrm{H}_{2} \mathrm{O}$ & $<7.0(-08)$ & $6.9(-07)$ & $\mathrm{Y}$ & & $\mathbf{H}_{2} \mathbf{S}$ & $5.0(-10)$ & $4.0(-12)$ & & \\
\hline $\mathrm{H}_{3} \mathrm{CO}^{+}$ & $<3.1(-09)$ & $5.3(-11)$ & $\mathrm{Y}$ & 14 & $\mathrm{HC}_{3} \mathrm{~N}$ & $1.6(-08)$ & $1.6(-08)$ & $\mathrm{Y}$ & \\
\hline $\mathrm{HC}_{3} \mathrm{NH}^{+}$ & $1.0(-10)$ & $1.6(-11)$ & $\mathrm{Y}$ & & $\mathrm{HC}_{5} \mathrm{~N}$ & $5.6(-09)$ & $3.4(-09)$ & Y & 3 \\
\hline $\mathrm{HC}_{7} \mathrm{~N}$ & $1.2(-09)$ & $1.5(-10)$ & $\mathrm{Y}$ & 3 & $\mathrm{HC}_{9} \mathrm{~N}$ & $8.4(-10)$ & $2.3(-11)$ & & 3 \\
\hline $\mathrm{HCN}$ & $2.0(-08)$ & $7.8(-08)$ & $\mathrm{Y}$ & & $\mathrm{HCNH}^{+}$ & $2.0(-09)$ & $5.2(-10)$ & Y & \\
\hline $\mathrm{HCNO}$ & $<1.3(-12)$ & $2.4(-13)$ & $\mathrm{Y}$ & 10 & $\mathrm{HCOOH}$ & $2.0(-10)$ & $4.2(-10)$ & Y & \\
\hline $\mathrm{HCO}^{+}$ & $8.0(-09)$ & $5.0(-09)$ & Y & & $\mathbf{H C S}^{+}$ & $4.0(-10)$ & $4.3(-12)$ & & \\
\hline $\mathrm{HNC}$ & $2.0(-08)$ & $6.8(-08)$ & Y & & $\mathrm{HNC}_{3}$ & $6.0(-11)$ & $1.5(-11)$ & $\mathrm{Y}$ & \\
\hline HNCO & $5.7(-10)$ & $2.4(-11)$ & & 10 & $\mathrm{~N}_{2} \mathrm{H}^{+}$ & $4.0(-10)$ & $3.8(-11)$ & & \\
\hline $\mathrm{NH}_{3}$ & $2.0(-08)$ & $2.9(-08)$ & Y & & NO & $3.0(-08)$ & $3.9(-09)$ & $\mathrm{Y}$ & \\
\hline $\mathrm{O}_{2}$ & $<7.7(-08)$ & $3.9(-08)$ & $\mathrm{Y}$ & & OCS & $2.0(-09)$ & $1.4(-11)$ & & \\
\hline $\mathrm{OH}$ & $2.7(-07)$ & $1.5(-08)$ & & 4 & SO & $1.0(-08)$ & $1.4(-10)$ & & 7 \\
\hline $\mathrm{SO}_{2}$ & $1.0(-09)$ & $2.1(-12)$ & & & & & & & \\
\hline
\end{tabular}

Notes. The best fit time is $1.7 \times 10^{5}$ years. Of the 63 species below, 41 agree, to within an order of magnitude, with observations. The "Ref." column gives references for the observed values. ${ }^{(1)} a(b)=a \times 10^{b}$.

References. (1) See Smith et al. (2004) and Walsh et al. (2009) for source; (2) Bell et al. (1999); (3) Kalenskii et al. (2004); (4) Suutarinen et al. (2011); (5) Sakai et al. (2010a); (6) Fosse et al. (2001); (7) Lique et al. (2006); (8) Lovas et al. (2006); (9) Remijan et al. (2006); (10) Marcelino et al. (2008); (11) Snyder et al. (2006); (12) Guélin et al. (1998); (13) Marcelino et al. (2007); (14) Minh et al. (1993).

Table 5. List of species whose observed abundances are matched by only one of RATE12 or kida.uva.2011.

\begin{tabular}{|c|c|c|c|c|c|}
\hline Species & Observed & RATE12 & Agree? & KIDA & Agree? \\
\hline $\mathrm{C}_{3} \mathrm{O}$ & $1.0(-10)$ & $1.4(-10)$ & $\mathrm{Y}$ & $6.8(-09)$ & \\
\hline $\mathrm{CH}_{3} \mathrm{CHCH}_{2}$ & $4.0(-09)$ & $1.1(-09)$ & $\mathrm{Y}$ & $0.0(+00)$ & \\
\hline $\mathrm{HCOOH}$ & $2.0(-10)$ & $4.2(-10)$ & Y & $8.0(-09)$ & \\
\hline $\mathrm{HC}_{3} \mathrm{NH}+$ & $1.0(-10)$ & $1.6(-11)$ & $\mathrm{Y}$ & $1.3(-09)$ & \\
\hline $\mathrm{CH}_{3} \mathrm{CHO}$ & $6.0(-10)$ & $2.3(-10)$ & $\mathrm{Y}$ & $3.5(-12)$ & \\
\hline $\mathrm{H}_{2} \mathrm{O}$ & $<7.0(-08)$ & $6.9(-07)$ & Y & $4.1(-06)$ & \\
\hline $\mathrm{HNC}_{3}$ & $6.0(-11)$ & $1.5(-11)$ & $\mathrm{Y}$ & $8.9(-10)$ & \\
\hline $\mathrm{C}_{3} \mathrm{H}$ & $8.0(-11)$ & $6.9(-10)$ & Y & $5.8(-09)$ & \\
\hline $\mathrm{C}_{2} \mathrm{O}$ & $6.0(-11)$ & $1.4(-11)$ & $\mathrm{Y}$ & $5.8(-13)$ & \\
\hline $\mathrm{CH}_{3} \mathrm{C}_{4} \mathrm{H}$ & $1.8(-10)$ & $7.6(-13)$ & & $1.1(-10)$ & Y \\
\hline $\mathrm{CH}_{3} \mathrm{C}_{3} \mathrm{~N}$ & $4.5(-11)$ & $6.5(-10)$ & & $2.2(-10)$ & Y \\
\hline $\mathrm{C}_{2} \mathrm{~S}$ & $3.4(-09)$ & $9.9(-13)$ & & $3.0(-09)$ & Y \\
\hline $\mathrm{N}_{2} \mathrm{H}^{+}$ & $4.0(-10)$ & $3.8(-11)$ & & $5.9(-11)$ & Y \\
\hline $\mathrm{CH}_{2} \mathrm{CN}$ & $5.0(-09)$ & $1.8(-10)$ & & $1.7(-09)$ & Y \\
\hline $\mathrm{C}_{7} \mathrm{H}$ & $1.5(-11)$ & $4.1(-10)$ & & $9.6(-11)$ & $\mathrm{Y}$ \\
\hline
\end{tabular}

Notes. The abundances shown are those seen the "best-fit" time of each reaction network. These are $1.7 \times 10^{5}$ years for RATE 12 and $2.5 \times 10^{5}$ years for kida.uva.2011. ${ }^{(1)} a(b)=a \times 10^{b}$. 


\subsection{Carbon-rich circumstellar envelope model}

In this section, we report the results of a simple chemical model for the CSE of a carbon-rich AGB star, using the new RATE12 reaction network to compute the chemical evolution. For a constant mass-loss rate, the star has a uniform, spherically symmetric outflow which can be easily modelled (Millar 1998).

\subsubsection{CSE model details}

The model for the CSE is based on that of Millar et al. (2000) using parameters appropriate to IRC +10216 but ignoring the presence of dust and gas shells in the outflow, the inclusion of which gives a significant improvement in agreement between models and observation in both column densities and spatial distributions (Cordiner \& Millar 2009). The cool, expanding outer envelope of the carbon-rich AGB star, IRC+10216, is one of the most important extra-terrestrial environments for the study of gasphase chemical kinetics due to the abundance and diversity of the different molecules detected in the envelope (e.g. Cernicharo et al. 2000). IRC+10216 has therefore been the subject of intensive ongoing astrochemical study (e.g. Bieging \& Rieu 1988; Guélin et al. 1999; Cordiner \& Millar 2009; De Beck et al. 2012; Agúndez et al. 2012), with over 80 different molecules detected in this source to date. We assume the central star loses mass at a uniform rate of $1.5 \times 10^{-5} M_{\odot} \mathrm{yr}^{-1}$ (De Beck et al. 2012). The ejected matter expands in a spherically-symmetric outflow at a radial velocity of $14.5 \mathrm{~km} \mathrm{~s}^{-1}$, resulting in a gas density distribution that falls as $1 / r^{2}$, where $r$ is the distance from the central star. The adopted temperature profile in the envelope is based on an empirical fit to the gas kinetic temperature profile derived by Crosas \& Menten (1997), the form of which is given in Eq. (1) of Cordiner \& Millar (2009). Parent species (with abundances taken from Agúndez et al. 2012; and Cordiner $\&$ Millar 2009; see Table 6), are injected at the inner radius, $r_{i}=2 \times 10^{15} \mathrm{~cm}$, where the molecular hydrogen number density is $n_{\mathrm{H}_{2}}=3.2 \times 10^{6} \mathrm{~cm}^{-3}$, and the kinetic temperature of the gas is $221 \mathrm{~K}$. The standard interstellar radiation field (Draine 1978) is assumed to impinge on the outside of the envelope from all directions, and is attenuated by a radial visual extinction of $A_{V}=6.9 \mathrm{mag}$ at $r_{i}$. The radiation flux inside the envelope is calculated assuming purely absorbing grains. Extinction of the incident radiation is derived using the Bohlin et al. (1978) standard interstellar gas-to-dust ratio and the extinction curve tabulated by Savage \& Mathis (1979). Photodissociation of CO is assumed to occur through absorption of $100 \mathrm{~nm}$ photons, using a single-band approximation to account for self-shielding (Morris \& Jura 1983).

The chemical kinetic equations are solved as a function of radius as material traverses the CSE, until it reaches the final radius, $r_{\mathrm{f}}=7 \times 10^{17} \mathrm{~cm}$, at which point the density has decreased to $n_{\mathrm{H}_{2}}=26 \mathrm{~cm}^{-3}$, the radial extinction is $A_{\mathrm{V}}=0.02 \mathrm{mag}$ and the majority of molecules (apart from self-shielded $\mathrm{H}_{2}$ ) are dissociated.

\subsubsection{CSE model results}

In Table 7 we list calculated and observed column densities for those species detected in IRC +10216 . We obtain a match between observed and calculated column densities (to within an order of magnitude, as denoted by the "Agree" column) for 31 out of 46 of those species. In general, agreement is very good for the hydrocarbons, nitriles and anions, but is poor for $\mathrm{CH}_{3} \mathrm{CCH}$ and for the phosphorus-bearing species, which indicates that our
Table 6. Initial abundances of parent species relative to $\mathrm{H}_{2}$.

\begin{tabular}{lclc}
\hline \hline Species & Abundance & Species & Abundance $^{1}$ \\
\hline $\mathrm{He}$ & $1.0(-1)$ & $\mathrm{CH}_{4}$ & $3.5(-6)$ \\
$\mathrm{NH}_{3}$ & $2.0(-6)$ & $\mathrm{H}_{2} \mathrm{O}$ & $1.0(-7)$ \\
$\mathrm{HF}$ & $8.0(-9)$ & $\mathrm{Mg}$ & $1.0(-5)$ \\
$\mathrm{C}_{2} \mathrm{H}_{2}$ & $8.0(-5)$ & $\mathrm{HCN}$ & $2.0(-5)$ \\
$\mathrm{N}_{2}$ & $2.0(-4)$ & $\mathrm{C}_{2} \mathrm{H}_{4}$ & $2.0(-8)$ \\
$\mathrm{CO}$ & $6.0(-4)$ & $\mathrm{SiH}_{4}$ & $2.2(-7)$ \\
$\mathrm{H}_{2} \mathrm{~S}$ & $4.0(-9)$ & $\mathrm{HCl}$ & $1.0(-7)$ \\
$\mathrm{CS}$ & $7.0(-7)$ & $\mathrm{HCP}$ & $2.5(-8)$ \\
$\mathrm{SiO}$ & $1.8(-7)$ & $\mathrm{SiC}_{2}$ & $2.0(-7)$ \\
$\mathrm{SiS}$ & $1.3(-6)$ & & \\
\hline
\end{tabular}

Notes. ${ }^{(1)} a(b)=a \times 10^{b}$.

understanding of the chemistry of these species in carbon-rich CSEs is not yet complete.

Compared with the previous models for large molecules in IRC +10216 by Millar et al. (2000, MHB00) and Cordiner \& Millar (2009, CM09), the new RATE12 chemical network results in significantly better agreement between calculated and observed column densities of the larger cyanopolyynes $\left(\mathrm{HC}_{2 n+1} \mathrm{~N}\right.$; $n=2,3,4)$. The physical model and initial conditions for the CSE in the present model are more similar to those of CM09 than MHB00, so comparison with the results of CM09 is more relevant. Whereas, the calculated column densities for $\mathrm{HC}_{5} \mathrm{~N}, \mathrm{HC}_{7} \mathrm{~N}$ and $\mathrm{HC}_{9} \mathrm{~N}$ from $\mathrm{CM} 09$ were about an order-of-magnitude too large, we find that using the RATE12 model the column densities of these species are accurately reproduced, within about a factor of two. The marked differences between the cyanopolyyne abundances calculated by the two chemical networks are shown in Fig. 2 (top left panel), where the dotted lines show the results of the CM09 network and the solid lines are using RATE12 (in this figure, the same physical model and initial conditions are used for both networks). Using the CM09 network, the cyanopolyyne abundances peak closer to the star and reach higher peak values. This is because CM09/MHB00 include the following class of neutral-neutral reactions (for $n=1-11$ ) that are absent from RATE12 (except for the case of $n=1$, which is included and has an energy barrier of $770 \mathrm{~K}$ ),

$\mathrm{C}_{2 n} \mathrm{H}+\mathrm{HCN} \longrightarrow \mathrm{HC}_{2 n+1} \mathrm{~N}+\mathrm{H}$.

These reactions dominate the synthesis of cyanopolyynes in MHB00 and CM09 whereas in the RATE12 model, they are produced mainly from the reaction of $\mathrm{CN}$ with (poly-)acetylenes,

$\mathrm{HC}_{2 n} \mathrm{H}+\mathrm{CN} \longrightarrow \mathrm{HC}_{2 n+1} \mathrm{~N}+\mathrm{H}$.

For clarity, $\mathrm{HC}_{3} \mathrm{~N}$ is not shown in Fig. 2 as it exhibits the opposite behaviour to the larger cyanopolyynes; its production rate in both models is dominated by Reaction 9, whereas in CM09, a larger photodissociation rate for the molecule, as well as the inclusion of additional destruction reactions with polyynes, leads to a reduction in the overall $\mathrm{HC}_{3} \mathrm{~N}$ abundance.

Other species with improved matches, when compared with previous models, include $\mathrm{C}_{3} \mathrm{~N}$ and $\mathrm{C}_{3} \mathrm{O}$, which are greater by factors of 20 and 200, respectively, using the new network. This brings these into better agreement with observations (see Table 7). In CM09 and MHB00, $\mathrm{C}_{3} \mathrm{~N}$ was produced primarily from $\mathrm{HC}_{3} \mathrm{~N}$ photolysis, whereas in RATE12 the following reaction dominates its synthesis,

$\mathrm{C}_{2}+\mathrm{HCN} \longrightarrow \mathrm{C}_{3} \mathrm{~N}+\mathrm{H}$. 
Table 7. Calculated and observed column densities $\left(\mathrm{cm}^{-2}\right)$ for a carbon-rich CSE.

\begin{tabular}{|c|c|c|c|c|c|c|c|c|c|}
\hline Species & Calculated & Observed & Agree? & Ref. & Species & Calculated & Observed & Agree? & Ref. \\
\hline $\mathrm{C}$ & $1.9(16)^{1}$ & $1.1(16)$ & $\mathrm{Y}$ & 1 & $\mathrm{C}_{2}$ & $4.2(15)$ & $7.9(14)$ & $\mathrm{Y}$ & 2 \\
\hline $\mathrm{C}_{2} \mathrm{H}$ & $9.7(15)$ & $3-5(15)$ & $\mathrm{Y}$ & 1 & $\mathrm{CN}$ & $4.1(15)$ & 1.1(15) & $\mathrm{Y}$ & 2 \\
\hline $\mathrm{CN}^{-}$ & 7.0(11) & $5(12)$ & $\mathrm{Y}$ & 3 & $\mathrm{HCO}^{+}$ & $1.2(12)$ & $3-4(12)$ & $\mathrm{Y}$ & 1,23 \\
\hline $\mathrm{CH}_{2} \mathrm{NH}$ & $2.3(11)$ & 9(12) & & 21 & $\mathrm{C}_{3}$ & $1.8(14)$ & 1(15) & $\mathrm{Y}$ & 1 \\
\hline $\mathrm{C}_{3} \mathrm{H}$ & $1.4(14)$ & $3-7(13)$ & $\mathrm{Y}$ & 1,4 & $l-\mathrm{C}_{3} \mathrm{H}_{2}$ & $1.1(13)$ & $3(12)$ & Y & 24 \\
\hline$c-\mathrm{C}_{3} \mathrm{H}_{2}$ & $5.8(13)$ & 2(13) & $\mathrm{Y}$ & 1 & $\mathrm{CH}_{2} \mathrm{CN}$ & 4.1(12) & $8.4(12)$ & $\mathrm{Y}$ & 5 \\
\hline $\mathrm{CH}_{3} \mathrm{CCH}$ & $4.9(11)$ & $1.6(13)$ & & 5 & $\mathrm{CH}_{3} \mathrm{CN}$ & $5.4(12)$ & $6-30(12)$ & $\mathrm{Y}$ & 1,5 \\
\hline $\mathrm{C}_{4} \mathrm{H}$ & $6.5(14)$ & $2-9(15)$ & Y & 1 & $\mathrm{C}_{4} \mathrm{H}^{-}$ & $1.3(13)$ & 7(11) & & 6 \\
\hline $\mathrm{C}_{3} \mathrm{~N}$ & 5.1(14) & $2-4(14)$ & $\mathrm{Y}$ & 1 & $\mathrm{C}_{3} \mathrm{~N}^{-}$ & $1.0(12)$ & $2(12)$ & $\mathrm{Y}$ & 8 \\
\hline $\mathrm{HC}_{3} \mathrm{~N}$ & $4.8(14)$ & $1-2(15)$ & $\mathrm{Y}$ & 1 & $\mathrm{CH}_{2} \mathrm{CHCN}$ & $3.6(10)$ & $5(12)$ & & 5 \\
\hline $\mathrm{C}_{2} \mathrm{~S}$ & $1.4(13)$ & $9-15(13)$ & $\mathrm{Y}$ & 9,10 & $\mathrm{C}_{5}$ & $1.5(14)$ & 1(14) & $\mathrm{Y}$ & 1 \\
\hline $\mathrm{C}_{5} \mathrm{H}$ & $4.0(13)$ & $2-50(13)$ & $Y$ & 1 & $\mathrm{C}_{3} \mathrm{~S}$ & $1.3(13)$ & $6-11(13)$ & $\mathrm{Y}$ & 9,10 \\
\hline $\mathrm{C}_{6} \mathrm{H}$ & $5.7(14)$ & 7(13) & $\mathrm{Y}$ & 5 & $\mathrm{C}_{6} \mathrm{H}^{-}$ & $8.3(13)$ & 4(12) & & 5 \\
\hline $\mathrm{C}_{5} \mathrm{~N}$ & $3.5(13)$ & $3-6(12)$ & $\mathrm{Y}$ & 1,4 & $\mathrm{C}_{5} \mathrm{~N}^{-}$ & $7.8(12)$ & $3(12)$ & $\mathrm{Y}$ & 7 \\
\hline $\mathrm{HC}_{5} \mathrm{~N}$ & $1.4(14)$ & $2-3(14)$ & $\mathrm{Y}$ & 1 & $\mathrm{C}_{7} \mathrm{H}$ & $7.3(13)$ & $1-2(12)$ & & 1,4 \\
\hline $\mathrm{C}_{8} \mathrm{H}$ & $1.2(14)$ & 5(12) & & 1 & $\mathrm{C}_{8} \mathrm{H}^{-}$ & $2.9(12)$ & 2(12) & $\mathrm{Y}$ & 11 \\
\hline $\mathrm{HC}_{7} \mathrm{~N}$ & $4.7(13)$ & $1(14)$ & $\mathrm{Y}$ & 1 & $\mathrm{HC}_{9} \mathrm{~N}$ & $1.3(13)$ & $3(13)$ & $\mathrm{Y}$ & 1 \\
\hline $\mathrm{CP}$ & $2.1(12)$ & $1(14)$ & & 12 & $\mathrm{PN}$ & $5.5(09)$ & $1(13)$ & & 12 \\
\hline $\mathrm{C}_{2} \mathrm{P}$ & $8.0(09)$ & $1(12)$ & & 13 & $\mathrm{SiC}$ & $9.8(12)$ & $6(13)$ & Y & 14 \\
\hline $\mathrm{SiC}_{2}$ & $1.3(15)$ & $2(14)$ & $\mathrm{Y}$ & 15 & $\mathrm{SiC}_{3}$ & $1.6(12)$ & $4(12)$ & $\mathrm{Y}$ & 16 \\
\hline $\mathrm{SiC}_{4}$ & $6.8(10)$ & $7(12)$ & & 17 & $\mathrm{SiN}$ & $2.4(12)$ & $4(13)$ & & 18 \\
\hline SiNC & $1.2(09)$ & $2(12)$ & & 19 & $\mathrm{C}_{3} \mathrm{O}$ & $6.0(11)$ & $1(12)$ & $\mathrm{Y}$ & 20 \\
\hline $\mathrm{H}_{2} \mathrm{CS}$ & $3.5(11)$ & 1(13) & & 5 & $\mathrm{H}_{2} \mathrm{CO}$ & $1.5(11)$ & $5(12)$ & & 22 \\
\hline
\end{tabular}

Notes. Of the 46 species below, 31 agree, to within an order of magnitude, with observations. The "Ref." column gives references for the observed values. ${ }^{(1)} a(b)=a \times 10^{b}$.

References. (1) See references in Table 5 of Millar et al. (2000); (2) Bakker et al. (1997); (3) Agúndez et al. (2010); (4) Cernicharo et al. (2000); (5) Agúndez et al. (2008); (6) Cernicharo et al. (2007); (7) Cernicharo et al. (2008) ; (8) Thaddeus et al. (2008); (9) Cernicharo et al. (1987); (10) Bell et al. (1993); (11) Remijan et al. (2007); (12) Milam et al. (2008); (13) Halfen et al. (2008); (14) Cernicharo et al. (1989); (15) Thaddeus et al. (1984); (16) Apponi et al. (1999); (17) Ohishi et al. (1989); (18) Turner (1992); (19) Guélin et al. (2004); (20) Tenenbaum et al. (2006); (21) Tenenbaum et al. (2010); (22) Ford et al. (2004); (23) Pulliam et al. (2011); (24) Cernicharo et al. (1991).

The carbon-chain oxide, $\mathrm{C}_{3} \mathrm{O}$, is assumed to originate via the recombination of $\mathrm{H}_{3} \mathrm{C}_{3} \mathrm{O}^{+}$and $\mathrm{H}_{2} \mathrm{C}_{3} \mathrm{O}^{+}$in RATE12 and CM09. However, the production of $\mathrm{H}_{3} \mathrm{C}_{3} \mathrm{O}^{+}$is much more rapid in RATE12 due to the inclusion of the radiative association reaction,

$\mathrm{C}_{2} \mathrm{H}_{3}^{+}+\mathrm{CO} \longrightarrow \mathrm{H}_{3} \mathrm{C}_{3} \mathrm{O}^{+}+h v$,

which is absent from CM09. The resulting enhanced $\mathrm{H}_{3} \mathrm{C}_{3} \mathrm{O}^{+}$ abundance then leads to a substantially increased $\mathrm{C}_{3} \mathrm{O}$ yield.

The sulphuretted carbon chain, $\mathrm{C}_{4} \mathrm{~S}$, is another species for which the calculated abundance has changed significantly from CM09. The abundance is an order of magnitude less when using the new chemistry. In the CM09 model, $\mathrm{C}_{4} \mathrm{~S}$ was synthesised mainly via the sulphur exchange reaction,

$\mathrm{C}_{4} \mathrm{H}+\mathrm{S} \longrightarrow \mathrm{C}_{4} \mathrm{~S}+\mathrm{H}$

for which the analogous reaction involving $\mathrm{C}_{2} \mathrm{H}$ was measured in the laboratory by Smith et al. (2004). The unmeasured $\mathrm{C}_{4} \mathrm{H}+\mathrm{S}$ reaction is not included in RATE12, and the primary $\mathrm{C}_{4} \mathrm{~S}$ production mechanism is via the dissociative recombination of $\mathrm{HC}_{4} \mathrm{~S}^{+}$.

\subsection{Impact of anions on the CSE chemistry}

Polyyne anions have been included in models of circumstellar envelopes since the work of Millar et al. (2000). Produced predominantly by radiative electron attachment to neutral polyynes, the polyyne anions become abundant inside the main molecular shell at a radius, $r \sim 10^{16}-10^{17} \mathrm{~cm}$ (see Fig. 2, bottom left panel). $\mathrm{C}_{6} \mathrm{H}^{-}$is the most abundant anion in the CSE as a result of the large $\mathrm{C}_{6} \mathrm{H}$ abundance and its large electron attachment rate (the bare carbon chain anion, $\mathrm{C}_{7}^{-}$, also reaches a similar abundance).

The presence of polyyne anions boosts the abundances of neutral polyynes towards larger radii $\left(\sim 10^{17} \mathrm{~cm}\right)$, as shown by the solid lines in Fig. 2 (top right panel). The main source of polyynes at these radii is from photodetachment of their respective anions (as studied in the laboratory by Best et al. 2011),

$\mathrm{C}_{n} \mathrm{H}^{-}+h v \longrightarrow \mathrm{C}_{n} \mathrm{H}+\mathrm{e}^{-}$.

The presence of free electrons can thus have a shielding effect on the polyynes because in the presence of UV radiation, anions tend to undergo electron detachment rather than photodissociation.

In molecular clouds, polyyne anions can have significant effects on the carbon-chain chemistry as a result of their high reactivity (Walsh et al. 2009; Cordiner \& Charnley 2012). In contrast, the presence of anions in a carbon-rich circumstellar envelope has a greater impact on the chemistry as a result of their effect on the ionisation balance. Anions affect the ionisation balance because they can remove a significant fraction of free electrons from the gas. For $r \approx 3 \times 10^{16}-1 \times 10^{17} \mathrm{~cm}$, the presence of anions reduces the free electron number density by over an order of magnitude. A reduction in the electron number density leads to reduced recombination rates, and consequently more cations build up in the CSE (as shown by comparison of the solid and dashed lines for a selection of the more abundant cations in the lower-right panel of Fig. 2). Within the main molecular shell, the majority of cations exhibit increased abundances, enhanced by factors $\sim 10-1000$. For atomic cations, however, the opposite effect occurs because mutual neutralisation is more rapid than 

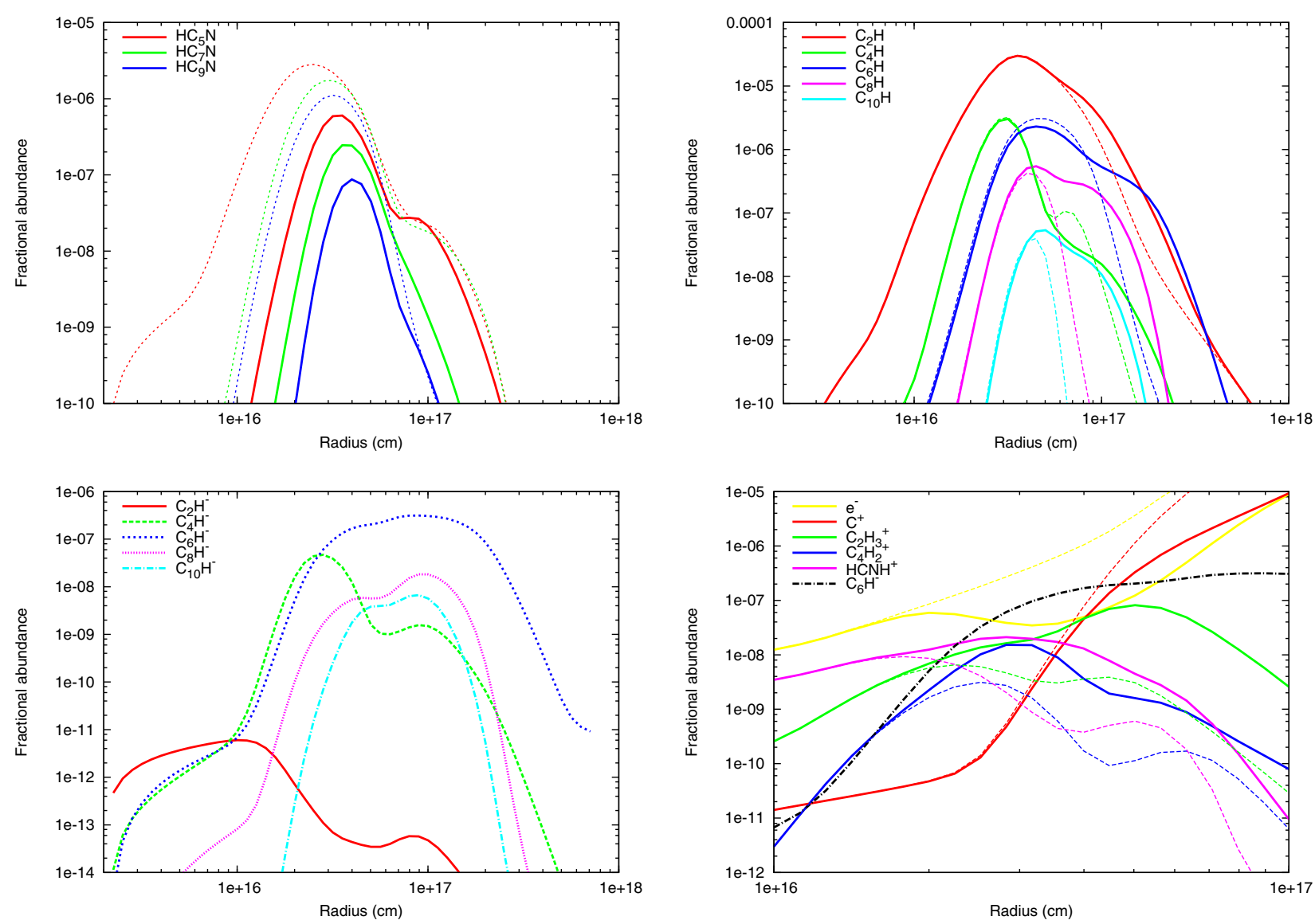

Fig. 2. Top left: plot of the fractional abundances, relative to $\mathrm{H}_{2}$, of cyanopolyynes as a function of envelope radius using the RATE12 model (solid lines) compared with the results from CM09 (dotted lines). Top right: plot of fractional abundances of polyynes as a function of envelope radius for the RATE12 model including anion chemistry (solid lines) and excluding anion chemistry (dashed lines). Bottom left: plot of fractional abundances of polyyne anions as a function of envelope radius. Bottom right: comparison of the fractional abundances of various cations and electrons, including anion chemistry (solid lines) and excluding anion chemistry (dashed lines). The $\mathrm{C}_{6} \mathrm{H}^{-}$fractional abundance for the "anions included" model is shown, for reference, with a dot-dashed line.

radiative recombination, such that, when the abundance of anions becomes sufficiently large, the abundance of atomic cations fall. This is illustrated for the case of $\mathrm{C}^{+}$in Fig. 2 (lower-right panel). The abundance of $\mathrm{C}_{6} \mathrm{H}^{-}$is also shown for reference; it exceeds the free electron abundance by about a factor of 4 at radial distances $(3-4) \times 10^{16} \mathrm{~cm}$, at which point it is the dominant charge carrier in the envelope.

The increased abundances of cations have knock-on effects on the chemistry, for example, in the abundances of their respective recombination products. The $\mathrm{C}_{2} \mathrm{H}_{3}^{+}$and $\mathrm{C}_{2} \mathrm{H}_{4}^{+}$cations recombine to $\mathrm{C}_{2} \mathrm{H}$ (plus products), so their elevated abundances give rise to the enhancement in $\mathrm{C}_{2} \mathrm{H}$ seen at around $(1-3) \times$ $10^{17} \mathrm{~cm}$ in Fig. 2 (top-right panel). Other examples include $\mathrm{C}_{2} \mathrm{H}_{3}$ (produced from recombination of $\mathrm{C}_{2} \mathrm{H}_{4}^{+}$), which then reacts with $\mathrm{N}$ atoms to produce a corresponding enhancement in the $\mathrm{CH}_{2} \mathrm{CN}$ abundance.

Associative detachment reactions of polyyne anions with $\mathrm{H}$ atoms boost the abundances of the polyacetylenes $\left(\mathrm{HC}_{n} \mathrm{H}\right)$ due to the reaction,

$\mathrm{C}_{n} \mathrm{H}^{-}+\mathrm{H} \longrightarrow \mathrm{HC}_{n} \mathrm{H}+\mathrm{e}^{-}$

However, these reactions are only efficient in the outer envelope where the $\mathrm{H}$-atom abundance becomes sufficiently large. In the outer envelope the density is relatively low, so the resulting contributions to the total polyacetylene column densities are small.

\section{Summary}

In this paper, we have presented the new release of the UMIST database for Astrochemistry, RATE12, describing, in detail, the updates and new additions made. We have presented results from a dark cloud model and a circumstellar envelope model using the RATE12 network and shown that these models give resonable agreement with observations, even in the absence of grain-surface chemistry.

These codes, along with sample output files and instructions on their usage, are available for download from our website ${ }^{7}$. Also available for download, are the RATE12 reaction network and files listing surface binding energies of species, a statespecific deuterated reaction network, a singly-deuterated version of RATE12 and a list of the important deuterium exchange reactions, so that users can construct their own deuterated networks.

We have updated the search facility on the website, which now displays all available information pertaining to a particular reaction or species. The website includes considerably more information than previously, including plots of molecule abundances in each model. Users can explore the effect that changing each rate coefficient has on the overall results of each model.

Acknowledgements. We are grateful to E. van Dishoeck, E. Vigren, M. Röllig and R. Garrod for sending data and giving advice. We would also like to

7 http://www.udfa.net 
thank the referee for providing useful comments, which helped improve the paper. Research in molecular astrophysics at QUB, and in particular that of $\mathrm{DMcE}$, is supported by a grant from the STFC. VAMDC is funded under the "Combination of Collaborative Projects and Coordination and Support Actions" Funding Scheme of The Seventh Framework Program. Call topic: INFRA-20081.2.2 Scientific Data Infrastructure. Grant Agreement number: 239108.

\section{Appendix A: RATE12 references}

Original measurements, calculations and estimates are taken from the following sources: Adams \& Smith (1977), Adams et al. (1980), Adams et al. (1984), Adusei \& Fontijn (1994), Allen \& Robinson (1977), Andreazza et al. (1995), Andreazza \& Singh (1997), Anicich et al. (2003b), Anicich et al. (2003a), Anicich et al. (1977), Anicich et al. (1984), Anicich et al. (1990), Anicich (1993), Barckholtz et al. (2001), Barlow (1984), Barlow \& Dunn (1987), Baulch (2005), Baulch et al. (1992), Berteloite et al. (2010), Berteloite et al. (2010), Best et al. (2011), Bettens et al. (1999), Black (1975), Blake et al. (1986), Bocherel et al. (1996), Bohme et al. (1982), Brown \& Bolina (2007). Bruhns et al. (2010), Brunetti \& Liuti (1975). Canosa et al. (1997), Canosa et al. (2007), Carty et al. (2001), Cazaux \& Tielens (2002), Chastaing et al. (2000), Chastaing et al. (1998), Chastaing et al. (1999), Chastaing et al. (1999), Cohen \& Westberg (1991), Collings et al. (2004), Cordiner \& Millar (2009), Dalgarno et al. (1990), Danielsson et al. (2008), Daugey et al. (2005), Daugey et al. (2008), Decker et al. (2000), Drdla et al. (1989), Edridge (2010), Eichelberger et al. (2007), Elitzur \& de Jong (1978), Ercolano \& Storey (2006), Ferguson (1973), Field et al. (1980), Forte et al. (1989), Freeman et al. (1979), Frost et al. (1993), Fukuzawa \& Osamura (1997), Gannon et al. (2007), Garrod \& Herbst (2006), Gredel et al. (1989), Gu et al. (2009), Hamberg et al. (2007), Hamberg et al. (2010), Hamberg et al. (2010), Harada \& Herbst (2008), Harrison et al. (1986), Hasegawa \& Herbst (1993), Hawley et al. (1990), Hemsworth et al. (1974), Herbst (1983), Herbst et al. (1984), Herbst \& Leung (1986), Herbst et al. (1989a), Herbst \& Leung (1989), Herbst et al. (1989b), Herbst et al. (1989c), Herbst \& Leung (1990), Herbst et al. (2000), Herbst \& Osamura (2008), Herbst et al. (2010), Herrero et al. (2010), Hoobler \& Leone (1997), Huo et al. (2011), Iglesias (1977), Inomata \& Washida (1999), Johnson et al. (2000), Kaiser \& Gu (2009), Kalhori et al. (2002), Kamińska et al. (2008), Kern et al. (1988), Wakelam et al. (2012), Klippenstein et al. (2010), Kuan et al. (1999), Larsson et al. (2005), Laufer \& Fahr (2004), Lawson et al. (2011), Le Picard et al. (2002), Leung et al. (1984), Lias \& Ausloos (1987), Liddy et al. (1975), Lin \& Lucchese (2001), Loison \& Bergeat (2004), Loison \& Bergeat (2009), Loison et al. (2012), Luca et al. (2002), Martinez et al. (2008), Martinez et al. (2010), McEwan et al. (1980), McEwan et al. (1998), Midey et al. (2008), Millar et al. (1985), Millar et al. (1986), Millar et al. (1987), Millar et al. (1988), Millar \& Herbst (1990), Millar (1991), Millar et al. (1991), Millar et al. (1997b), Millar et al. (2000), Millar et al. (2007), Milligan et al. (2002), Mitchell et al. (1977), Mitchell et al. (1978), Mitchell (1984), Montaigne et al. (2005), Moran \& Hamill (1963), Nahar \& Pradhan (1997), Nejad \& Millar (1988), Neufeld \& Wolfire (2009), Nguyen et al. (2006), Novotný et al. (2010), Öberg et al. (2005), Öberg et al. (2009a), Öjekull et al. (2004), Osamura et al. (1999), Pequignot \& Aldrovandi (1986), Petrie et al. (1991), Petrie et al. (2003), Petrie \& Herbst (1997), Petuchowski et al. (1989), Pineau des Forêts et al. (1986), Plasil et al. (2011), Pradhan \& Dalgarno (1994), Prasad \& Huntress (1980), Quan et al. (2010), Rawlings et al. (1993), Rebrion et al. (1988), Roberge et al. (1991),
Röllig (2011), Röhrig \& Wagner (1994), Ruffle et al. (1999), Sidhu et al. (1992), Sims et al. (1993), Sims et al. (1994), Singh et al. (1999), Singh \& Andreazza (2000), Singleton \& Cvetanović (1988), Smith \& Adams (1985), Smith et al. (1988), Smith et al. (1994), Smith et al. (1997), Smith et al. (2004), Stancil et al. (1998), Stancil et al. (1998), Stancil et al. (1999), Stoliarov et al. (2000), Sun et al. (2008), Talbi et al. (1996), Tielens \& Hagen (1982), Tielens \& Allamandola (1987), Tsang \& Hampson (1986), van Dishoeck et al. (2006), van Dishoeck \& Black (1988), van Hemert \& van Dishoeck (2008), van Dishoeck (1988), Vigren et al. (2008), Vigren et al. (2009), Vigren et al. (2010a), Vigren et al. (2010b), Vigren et al. (2010c), Vigren et al. (2012), Vikor et al. (1999), Wakelam et al. (2009), Wakelam et al. (2010a), Walsh et al. (2009), Whyte \& Phillips (1983), Wilson et al. (1993), Wlodek et al. (1988), Woon \& Herbst (1996), Xu et al. (1999), Yamamoto et al. (1983), Yang et al. (2010), Yang et al. (2011), Zachariah \& Tsang (1995), Zhang et al. (2009), Zhaunerchyk et al. (2005).

\section{References}

Adams, N., \& Smith, D. 1977, Chem. Phys. Lett., 47, 383

Adams, N. G., Smith, D., \& Paulson, J. F. 1980, J. Chem. Phys., 72, 288

Adams, N. G., Smith, D., \& Millar, T. J. 1984, MNRAS, 211, 857

Adusei, G. Y., \& Fontijn, A. 1994, Symposium (International) on Combustion, 25,801

Agúndez, M., Fonfría, J. P., Cernicharo, J., Pardo, J. R., \& Guélin, M. 2008, A\&A, 479, 493

Agúndez, M., Cernicharo, J., Guélin, M., et al. 2010, A\&A, 517, L2

Agúndez, M., Fonfría, J. P., Cernicharo, J., et al. 2012, A\&A, 543, A48

Allen, M., \& Robinson, G. W. 1977, ApJ, 212, 396

Andreazza, C. M., \& Singh, P. D. 1997, MNRAS, 287, 287

Andreazza, C. M., Singh, P. D., \& Sanzovo, G. C. 1995, ApJ, 451, 889

Anicich, V. G. 1993, J. Phys. Chem. Ref. Data, 22, 1469

Anicich, V. G., Laudenslager, J. B., Huntress, W. T., \& Futrell, J. H. 1977, J. Chem. Phys., 67, 4340

Anicich, V. G., Blake, G. A., Kim, J. K., McEwan, M. J., \& Huntress, W. T. 1984, J. Phys. Chem., 88, 4608

Anicich, V. G., Sen, A. D., Huntress, W. T., \& McEwan, M. J. 1990, J. Chem. Phys., 93, 7163

Anicich, V., Aeronautics, U. S. N., Administration, S., \& (U.S.), J. P. L. 2003a, An Index of the Literature for Bimolecular Gas Phase Cation-Molecule Reaction Kinetics, JPL Publication (Jet Propulsion Laboratory, National Aeronautics and Space Administration)

Anicich, V. G., Wilson, P., \& McEwan, M. J. 2003b, J. Am. Soc. Mass Spectrom., 14,900

Apponi, A. J., McCarthy, M. C., Gottlieb, C. A., \& Thaddeus, P. 1999, ApJ, 516, L103

Bakker, E. J., van Dishoeck, E. F., Waters, L. B. F. M., \& Schoenmaker, T. 1997, A\&A, 323, 469

Barckholtz, C., Snow, T. P., \& Bierbaum, V. M. 2001, ApJ, 547, L171

Barlow, S. G. 1984, Ph.D. Thesis, University of Colorado

Barlow, S., \& Dunn, G. 1987, Int. J. Mass Spectrom. Ion Proc., 80, 227

Baulch, D. L. 2005, J. Phys. Chem. Ref. Data, 34, 757

Baulch, D. L., Cobos, C. J., Cox, R. A., et al. 1992, J. Phys. Chem. Ref. Data, 21,411

Bell, M. B., Avery, L. W., \& Feldman, P. A. 1993, ApJ, 417, L37

Bell, M. B., Feldman, P. A., Watson, J. K. G., et al. 1999, ApJ, 518, 740

Berteloite, C., Le Picard, S. D., Balucani, N., Canosa, A., \& Sims, I. R. 2010, Phys. Chem. Chem. Phys., 12, 3666

Best, T., Otto, R., Trippel, S., et al. 2011, ApJ, 742, 63

Bettens, R. P. A., Hansen, T. A., \& Collins, M. A. 1999, J. Chem. Phys., 111, 6322

Bieging, J. H., \& Rieu, N.-Q. 1988, ApJ, 329, L107

Biham, O., Furman, I., Pirronello, V., \& Vidali, G. 2001, ApJ, 553, 595

Black, J. H. 1975, Ph.D. Thesis, Harvard University

Blake, G. A., Anicich, V. G., \& Huntress, W. T. J. 1986, ApJ, 300, 415

Bocherel, P., Herbert, L. B., Rowe, B. R., et al. 1996, J. Phys. Chem., 100, 3063

Bohlin, R. C., Savage, B. D., \& Drake, J. F. 1978, ApJ, 224, 132

Bohme, D., Rakshit, A., \& Schiff, H. 1982, Chem. Phys. Lett., 93, 592

Brown, W. A., \& Bolina, A. S. 2007, MNRAS, 374, 1006

Bruhns, H., Kreckel, H., Miller, K., Urbain, X., \& Savin, D. 2010, Phys. Rev. A, 82 
Brunetti, B., \& Liuti, G. 1975, Z. Phys. Chem., 94, 19

Brünken, S., Gupta, H., Gottlieb, C. A., McCarthy, M. C., \& Thaddeus, P. 2007, ApJ, 664, L43

Brünken, S., Belloche, A., Martín, S., Verheyen, L., \& Menten, K. M. 2010, A\&A, 516, A109

Canosa, A., Sims, I. R., Travers, D., Smith, I. W. M., \& Rowe, B. R. 1997, A\&A, 323,644

Canosa, A., Páramo, A., Le Picard, S. D., \& Sims, I. R. 2007, Icarus, 187, 558

Carty, D., Le Page, V., Sims, I. R., \& Smith, I. W. 2001, Chem. Phys. Lett., 344, 310

Caselli, P., Hasegawa, T. I., \& Herbst, E. 1998, ApJ, 495, 309

Cazaux, S., \& Tielens, A. G. G. M. 2002, ApJ, 575, L29

Cernicharo, J., Gottlieb, C. A., Guelin, M., Thaddeus, P., \& Vrtilek, J. M. 1989, ApJ, 341, L25

Cernicharo, J., Gottlieb, C. A., Guelin, M., et al. 1991, ApJ, 368, L39

Cernicharo, J., Kahane, C., Guelin, M., \& Hein, H. 1987, A\&A, 181, L9

Cernicharo, J., Guélin, M., \& Kahane, C. 2000, A\&AS, 142, 181

Cernicharo, J., Guélin, M., Agúndez, M., et al. 2007, A\&A, 467, L37

Cernicharo, J., Guélin, M., Agúndez, M., McCarthy, M. C., \& Thaddeus, P. 2008, ApJ, 688, L83

Charnley, S. B. 1998, ApJ, 509, L121

Chastaing, D., James, P. L., Sims, I. R., \& Smith, I. W. M. 1998, Faraday Discuss., 109, 165

Chastaing, D., James, P. L., Sims, I. R., \& Smith, I. W. M. 1999, Phys. Chem. Chem. Phys., 1, 2247

Chastaing, D., Le Picard, S. D., \& Sims, I. R. 2000, J. Chem. Phys., 112, 8466

Cohen, N., \& Westberg, K. R. 1991, J. Phys. Chem. Ref. Data, 20, 1211

Collings, M. P., Anderson, M. A., Chen, R., et al. 2004, MNRAS, 354, 1133

Cordiner, M. A., \& Charnley, S. B. 2012, ApJ, 749, 120

Cordiner, M. A., \& Millar, T. J. 2009, ApJ, 697, 68

Cordiner, M. A., Charnley, S. B., Buckle, J. V., Walsh, C., \& Millar, T. J. 2011, ApJ, 730, L18

Crosas, M., \& Menten, K. M. 1997, ApJ, 483, 913

Cuppen, H. M., \& Herbst, E. 2005, MNRAS, 361, 565

Dalgarno, A., Du, M. L., \& You, J. H. 1990, ApJ, 349, 675

Danielsson, M., Hamberg, M., Zhaunerchyk, V., et al. 2008, Int. J. Mass Spectrom., 273, 111

Daugey, N., Caubet, P., Retail, B., et al. 2005, Phys. Chem. Chem. Phys., 7, 2921

Daugey, N., Caubet, P., Bergeat, A., Costes, M., \& Hickson, K. M. 2008, Phys

Chem. Chem. Phys., 10, 729

De Beck, E., Lombaert, R., Agúndez, M., et al. 2012, A\&A, 539, A108

Decker, B. K., Adams, N. G., \& Babcock, L. M. 2000, Int. J. Mass Spectrom., 195,185

Draine, B. T. 1978, ApJS, 36, 595

Drdla, K., Knapp, G. R., \& van Dishoeck, E. F. 1989, ApJ, 345, 815

Dubernet, M. L., Boudon, V., Culhane, J. L., et al. 2010, J. Quant. Spec. Radiat. Transf., 111, 2151

Edridge, J. L. 2010, Ph.D. Thesis, UCL (University College London)

Eichelberger, B., Snow, T. P., Barckholtz, C., \& Bierbaum, V. M. 2007, ApJ, 667, 1283

Elitzur, M., \& de Jong, T. 1978, A\&A, 67, 323

Ercolano, B., \& Storey, P. J. 2006, MNRAS, 372, 1875

Ferguson, E. E. 1973, At. Data Nucl. Data Tab., 12, 159

Field, D., Adams, N. G., \& Smith, D. 1980, MNRAS, 192, 1

Flower, D. R., Pineau des Forêts, G., \& Walmsley, C. M. 2004, A\&A, 427, 887

Ford, K. E. S., Neufeld, D. A., Schilke, P., \& Melnick, G. J. 2004, ApJ, 614, 990

Forte, L., Lien, M. H., Hopkinson, A. C., \& Bohme, D. K. 1989, Can. J. Chem., 67, 1576

Fosse, D., Cernicharo, J., Gerin, M., \& Cox, P. 2001, ApJ, 552, 168

Freeman, C. G., Harland, P. W., \& McEwan, M. J. 1979, MNRAS, 187, 441

Frost, M. J., Sharkey, P., \& Smith, I. W. M. 1993, J. Phys. Chem., 97, 12254

Fukuzawa, K., \& Osamura, Y. 1997, ApJ, 489, 113

Gannon, K. L., Glowacki, D. R., Blitz, M. A., et al. 2007, J. Phys. Chem. A, 111, 6679

Garrod, R. T., \& Herbst, E. 2006, A\&A, 457, 927

Garrod, R. T., Weaver, S. L. W., \& Herbst, E. 2008, ApJ, 682, 283

Graedel, T. E., Langer, W. D., \& Frerking, M. A. 1982, ApJS, 48, 321

Gredel, R., Lepp, S., Dalgarno, A., \& Herbst, E. 1989, ApJ, 347, 289

Gu, X., Kaiser, R. I., Mebel, A. M., et al. 2009, ApJ, 701, 1797

Guélin, M., Neininger, N., \& Cernicharo, J. 1998, A\&A, 335, L1

Guélin, M., Neininger, N., Lucas, R., \& Cernicharo, J. 1999, in The Physics and Chemistry of the Interstellar Medium, eds. V. Ossenkopf, J. Stutzki, \& G. Winnewisser, 326

Guélin, M., Muller, S., Cernicharo, J., McCarthy, M. C., \& Thaddeus, P. 2004, A\&A, 426, L49

Halfen, D. T., Clouthier, D. J., \& Ziurys, L. M. 2008, ApJ, 677, L101

Hamberg, M., Geppert, W. D., Thomas, R. D., et al. 2007, Mol. Phys., 105, 899

Hamberg, M., Österdahl, F., Thomas, R. D., et al. 2010, A\&A, 514, A83
Harada, N., \& Herbst, E. 2008, ApJ, 685, 272

Harrison, J., Whyte, A., \& Phillips, L. 1986, Chem. Phys. Lett., 129, 346

Hasegawa, T. I., \& Herbst, E. 1993, MNRAS, 261, 83

Hasegawa, T. I., Herbst, E., \& Leukng, C. M. 1992, ApJS, 82, 167

Hawley, M., Mazely, T., Randeniya, L., et al. 1990, Int. J. Mass Spectrom. Ion Proc., 97, 55

Hemsworth, R., Payzant, J., Schiff, H., \& Bohme, D. 1974, Chem. Phys. Lett., 26, 417

Herbst, E. 1983, ApJS, 53, 41

Herbst, E., \& Leung, C. M. 1986, ApJ, 310, 378

Herbst, E., \& Leung, C. M. 1989, ApJS, 69, 271

Herbst, E., \& Leung, C. M. 1990, A\&A, 233, 177

Herbst, E., \& Osamura, Y. 2008, ApJ, 679, 1670

Herbst, E., Smith, D., \& Adams, N. G. 1984, A\&A, 138, L13

Herbst, E., Defrees, D. J., \& Koch, W. 1989a, MNRAS, 237, 1057

Herbst, E., Millar, T. J., Wlodek, S., \& Bohme, D. K. 1989b, A\&A, 222, 205

Herbst, E., Smith, D., Adams, N. G., \& McIntosh, B. J. 1989c, J. Chem. Soc., Faraday Trans. 2, 85, 1655

Herbst, E., Terzieva, R., \& Talbi, D. 2000, MNRAS, 311, 869

Herbst, E., Roueff, E., \& Talbi, D. 2010, Mol. Phys., 108, 2171

Herrero, V. J., Galvez, O., Mate, B., \& Escribano, R. 2010, Phys. Chem. Chem. Phys., 12, 3164

Hoobler, R. J., \& Leone, S. R. 1997, J. Geophys. Res., 102, 28717

Hugo, E., Asvany, O., \& Schlemmer, S. 2009, J. Chem. Phys., 130, 164302

Huo, R.-P., Zhang, X., Huang, X.-R., Li, J.-L., \& Sun, C.-C. 2011, J. Phys. Chem. A, 115,3576

Iglesias, E. 1977, ApJ, 218, 697

Inomata, S., \& Washida, N. 1999, J. Phys. Chem. A, 103, 5023

Johnson, D. G., Blitz, M. A., \& Seakins, P. W. 2000, Phys. Chem. Chem. Phys., 2, 2549

Kaiser, R. I., \& Gu, X. 2009, J. Chem. Phys., 131, 104311

Kalenskii, S. V., Slysh, V. I., Goldsmith, P. F., \& Johansson, L. E. B. 2004, ApJ, 610,329

Kalhori, S., Viggiano, A. A., Arnold, S. T., et al. 2002, A\&A, 391, 1159

Kamińska, M., Vigren, E., Zhaunerchyk, V., et al. 2008, ApJ, 681, 1717

Kern, R. D., Singh, H. J., \& Wu, C. H. 1988, Int. J. Chem. Kinet., 20, 731

Klippenstein, S. J., Georgievskii, Y., \& McCall, B. J. 2010, J. Phys. Chem. A, 114,278

Kuan, W., Jiang, T., \& Chung, K. 1999, Phys. Rev. A, 60, 364

Larsson, M., Ehlerding, A., Geppert, W. D., et al. 2005, J. Chem. Phys., 122, 156101

Laufer, A. H., \& Fahr, A. 2004, Chem. Rev., 104, 2813

Lawson, P. A., Osborne, D., \& Adams, N. G. 2011, Int. J. Mass Spectrom., 304, 41

Le Picard, S. D., Canosa, A., Reignier, D., \& Stoecklin, T. 2002, Phys. Chem. Chem. Phys., 4, 3659

Le Teuff, Y. H., Millar, T. J., \& Markwick, A. J. 2000, A\&AS, 146, 157

Leung, C. M., Herbst, E., \& Huebner, W. F. 1984, ApJS, 56, 231

Lias, S. G., \& Ausloos, P. 1987, Int. J. Mass Spectrom. Ion Proc., 81, 165

Liddy, J. P., Freeman, C. G., \& McEwan, M. J. 1975, Astrophys. Lett., 16, 155

Lin, P., \& Lucchese, R. R. 2001, J. Chem. Phys., 114, 9350

Lique, F., Cernicharo, J., \& Cox, P. 2006, ApJ, 653, 1342

Loison, J.-C., \& Bergeat, A. 2004, Phys. Chem. Chem. Phys., 6, 5396

Loison, J.-C., \& Bergeat, A. 2009, Phys. Chem. Chem. Phys., 11, 655

Loison, J.-C., Halvick, P., Bergeat, A., Hickson, K. M., \& Wakelam, V. 2012, MNRAS, 421, 1476

Lovas, F. J., Remijan, A. J., Hollis, J. M., Jewell, P. R., \& Snyder, L. E. 2006, ApJ, 637, L37

Luca, A., Voulot, D., \& Gerlich, D. 2002, in WDS02 Proc. Contribution Papers, Part II, ed. J. Safrankova, 294

Marcelino, N., Cernicharo, J., Agúndez, M., et al. 2007, ApJ, 665, L127

Marcelino, N., Cernicharo, J., Tercero, B., \& Roueff, E. 2008, ApJ, 690, L27

Martinez, Jr., O., Betts, N. B., Villano, S. M., et al. 2008, ApJ, 686, 1486

Martinez, O., Yang, Z., Demarais, N. J., Snow, T. P., \& Bierbaum, V. M. 2010 ApJ, 720, 173

McCarthy, M. C., Gottlieb, C. A., Gupta, H., \& Thaddeus, P. 2006, ApJ, 652, L141

McEwan, M. J., Anicich, V. G., \& Huntress, Jr., W. T. 1980, in Interstellar Molecules, ed. B. H. Andrew, IAU Symp., 87, 299

McEwan, M. J., Scott, G. B., \& Anicich, V. G. 1998, Int. J. Mass Spectrom. Ion Proc., 172, 209

Midey, A., Dotan, I., \& Viggiano, A. A. 2008, J. Phys. Chem. A, 112, 3040

Milam, S. N., Halfen, D. T., Tenenbaum, E. D., et al. 2008, ApJ, 684, 618

Millar, T. J. 1991, A\&A, 242, 241

Millar, T. J. 1998, The Molecular Astrophysics of Stars and Galaxies, eds. T. W. Hartquist, \& D. A. Williams (Oxford: Clarendon Press), 4, 331

Millar, T. J., \& Herbst, E. 1990, A\&A, 231, 466

Millar, T. J., Adams, N. G., Smith, D., \& Clary, D. C. 1985, MNRAS, 216, 1025 
Millar, T. J., Adams, N. G., Smith, D., Lindinger, W., \& Villinger, H. 1986, MNRAS, 221, 673

Millar, T. J., Bennett, A., \& Herbst, E. 1987, MNRAS, 229, 41P

Millar, T. J., Defrees, D. J., McLean, A. D., \& Herbst, E. 1988, A\&A, 194, 250

Millar, T. J., Bennett, A., Rawlings, J. M. C., Brown, P. D., \& Charnley, S. B. 1991, A\&AS, 87, 585

Millar, T. J., Farquhar, P. R. A., \& Willacy, K. 1997a, A\&AS, 121, 139

Millar, T. J., MacDonald, G. H., \& Gibb, A. G. 1997b, A\&A, 325, 1163

Millar, T. J., Herbst, E., \& Bettens, R. P. A. 2000, MNRAS, 316, 195

Millar, T. J., Walsh, C., Cordiner, M. A., Ní Chuimín, R., \& Herbst, E. 2007, ApJ, 662, L87

Milligan, D. B., Wilson, P. F., Freeman, C. G., Meot-Ner, M., \& McEwan, M. J. 2002, J. Phys. Chem. A, 106, 9745

Minh, Y. C., Irvine, W. M., \& McGonagle, D. 1993, J. Korean Astron. Soc., 26, 99

Mitchell, G. F. 1984, ApJS, 54, 81

Mitchell, G. F., Kuntz, P. J., \& Ginsburg, J. L. 1977, ApJ, 212, 71

Mitchell, G. F., Kuntz, P. J., \& Ginsburg, J. L. 1978, ApJS, 38, 39

Montaigne, H., Geppert, W. D., Semaniak, J., et al. 2005, ApJ, 631, 653

Moran, T. F., \& Hamill, W. H. 1963, J. Chem. Phys., 39, 1413

Morris, M., \& Jura, M. 1983, ApJ, 264, 546

Nahar, S. N., \& Pradhan, A. K. 1997, ApJS, 111, 339

Nejad, L. A. M., \& Millar, T. J. 1988, MNRAS, 230, 79

Neufeld, D. A., \& Wolfire, M. G. 2009, ApJ, 706, 1594

Nguyen, T. L., Peeters, J., \& Vereecken, L. 2006, J. Phys. Chem. A, 110, 12166

Novotný, O., Buhr, H., Stützel, J., et al. 2010, J. Phys. Chem. A, 114, 4870

Öberg, K. I., van Broekhuizen, F., Fraser, H. J., et al. 2005, ApJ, 621, L33

Öberg, K. I., Garrod, R. T., van Dishoeck, E. F., \& Linnartz, H. 2009a, A\&A, 504,891

Öberg, K. I., Linnartz, H., Visser, R., \& van Dishoeck, E. F. 2009b, ApJ, 693, 1209

Öberg, K. I., van Dishoeck, E. F., \& Linnartz, H. 2009c, A\&A, 496, 281

Ohishi, M., Kaifu, N., Kawaguchi, K., et al. 1989, ApJ, 345, L83

Öjekull, J., Andersson, P. U., Någård, M. B., et al. 2004, J. Chem. Phys., 120, 7391

Osamura, Y., Fukuzawa, K., Terzieva, R., \& Herbst, E. 1999, ApJ, 519, 697

Pequignot, D., \& Aldrovandi, S. M. V. 1986, A\&A, 161, 169

Petrie, S., \& Herbst, E. 1997, ApJ, 491, 210

Petrie, S., Freeman, C. G., McEwan, M. J., \& Ferguson, E. E. 1991, MNRAS, 248, 272

Petrie, S., Millar, T. J., \& Markwick, A. J. 2003, MNRAS, 341, 609

Petuchowski, S. J., Dwek, E., Allen, J. E., J., \& Nuth, J. A. I. 1989, ApJ, 342, 406

Pineau des Forêts, G., Roueff, E., \& Flower, D. R. 1986, MNRAS, 223, 743

Plasil, R., Mehner, T., Dohnal, P., et al. 2011, ApJ, 737, 60

Pradhan, A., \& Dalgarno, A. 1994, Phys. Rev. A, 49, 960

Prasad, S. S., \& Huntress, W. T. J. 1980, ApJS, 43, 1

Pulliam, R. L., Edwards, J. L., \& Ziurys, L. M. 2011, ApJ, 743, 36

Quan, D., Herbst, E., Osamura, Y., \& Roueff, E. 2010, ApJ, 725, 2101

Rawlings, J. M. C., Drew, J. E., \& Barlow, M. J. 1993, MNRAS, 265, 968

Rebrion, C., Marquette, J., Rowe, B., \& Clary, D. 1988, Chem. Phys. Lett., 143, 130

Remijan, A. J., Hollis, J. M., Snyder, L. E., Jewell, P. R., \& Lovas, F. J. 2006, ApJ, 643, L37

Remijan, A. J., Hollis, J. M., Lovas, F. J., et al. 2007, ApJ, 664, L47

Rixon, G., Dubernet, M. L., Piskunov, N., et al. 2011, in AIP Conf. Ser. 1344, eds. A. Bernotas, R. Karazija, \& Z. Rudzikas, 107

Roberge, W. G., Jones, D., Lepp, S., \& Dalgarno, A. 1991, ApJS, 77, 287

Roberts, H., \& Millar, T. J. 2000, A\&A, 361, 388

Röhrig, M., \& Wagner, H. G. 1994, Symposium (International) on Combustion, 25,975

Röllig, M. 2011, A\&A, 530, A9

Ruffle, D. P., Bettens, R. P. A., Terzieva, R., \& Herbst, E. 1999, ApJ, 523, 678

Sakai, N., Saruwatari, O., Sakai, T., Takano, S., \& Yamamoto, S. 2010a, A\&A, 512, A31

Sakai, N., Shiino, T., Hirota, T., Sakai, T., \& Yamamoto, S. 2010b, ApJ, 718, L49

Savage, B. D., \& Mathis, J. S. 1979, ARA\&A, 17, 73

Sidhu, K. S., Miller, S., \& Tennyson, J. 1992, A\&A, 255, 453

Sims, I. R., Queffelec, J.-L., Travers, D., et al. 1993, Chem. Phys. Lett., 211, 461

Sims, I. R., Queffelec, J.-L., Defrance, A., et al. 1994, J. Chem. Phys., 100, 4229

Singh, P. D., \& Andreazza, C. M. 2000, ApJ, 537, 261
Singh, P. D., Sanzovo, G. C., Borin, A. C., \& Ornellas, F. R. 1999, MNRAS, 303,235

Singleton, D. L., \& Cvetanović, R. J. 1988, J. Phys. Chem. Ref. Data, 17, 1377

Smith, D., \& Adams, N. G. 1985, ApJ, 298, 827

Smith, D., Adams, N. G., Giles, K., \& Herbst, E. 1988, A\&A, 200, 191

Smith, D., Spanel, P., \& Millar, T. J. 1994, MNRAS, 266, 31

Smith, J. R., Kim, J. B., \& Lineberger, W. C. 1997, Phys. Rev. A, 55, 2036

Smith, I. W. M., Herbst, E., \& Chang, Q. 2004, MNRAS, 350, 323

Snyder, L. E., Hollis, J. M., Jewell, P. R., Lovas, F. J., \& Remijan, A. 2006, ApJ, 647,412

Stancil, P. C., Lepp, S., \& Dalgarno, A. 1998, ApJ, 509, 1

Stancil, P. C., Schultz, D. R., Kimura, M., et al. 1999, A\&AS, 140, 225

Stoliarov, S. I., Knyazev, V. D., \& Slagle, I. R. 2000, J. Phys. Chem. A, 104, 9687

Su, T., \& Chesnavich, W. J. 1982, J. Chem. Phys., 76, 5183

Sun, J., Tang, Y., Sun, H., et al. 2008, Chem. Phys. Lett., 463, 315

Suutarinen, A., Geppert, W. D., Harju, J., et al. 2011, A\&A, 531, A121

Talbi, D., Ellinger, Y., \& Herbst, E. 1996, A\&A, 314, 688

Tenenbaum, E. D., Apponi, A. J., Ziurys, L. M., et al. 2006, ApJ, 649, L17

Tenenbaum, E. D., Dodd, J. L., Milam, S. N., Woolf, N. J., \& Ziurys, L. M. 2010 ApJ, 720, L102

Thaddeus, P., Cummins, S. E., \& Linke, R. A. 1984, ApJ, 283, L45

Thaddeus, P., Gottlieb, C. A., Gupta, H., et al. 2008, ApJ, 677, 1132

Tielens, A. G. G. M., \& Hagen, W. 1982, A\&A, 114, 245

Tielens, A. G. G. M., \& Allamandola, L. J. 1987, in Interstellar Processes, eds. D. J. Hollenbach, \& H. A. Thronson, Jr., Astrophysics and Space Science Library, 134, 397

Troe, J. 1987, J. Chem. Phys., 87, 2773

Tsang, W., \& Hampson, R. F. 1986, J. Phys. Chem. Ref. Data, 15, 1087

Turner, B. E. 1992, ApJ, 388, L35

van Dishoeck, E. F. 1988, in Rate Coefficients in Astrochemistry, eds. T. J. Millar, \& D. A. Williams, Astrophys. Space Sci. Lib., 146, 49

van Dishoeck, E. F., \& Black, J. H. 1988, ApJ, 334, 771

van Dishoeck, E. F., Jonkheid, B., \& van Hemert, M. C. 2006, Faraday Discuss., 133,231

van Hemert, M., \& van Dishoeck, E. 2008, Chem. Phys., 343, 292

Vigren, E., Kamińska, M., Hamberg, M., et al. 2008, Phys. Chem. Chem. Phys., 10,4014

Vigren, E., Hamberg, M., Zhaunerchyk, V., et al. 2009, ApJ, 695, 317

Vigren, E., Hamberg, M., Zhaunerchyk, V., et al. 2010a, ApJ, 709, 1429

Vigren, E., Hamberg, M., Zhaunerchyk, V., et al. 2010b, ApJ, 722, 847

Vigren, E., Hamberg, M., Zhaunerchyk, V., et al. 2010c, Phys. Chem. Chem. Phys., 12, 11670

Vigren, E., Zhaunerchyk, V., Hamberg, M., et al. 2012, ApJ, 757, 34

Vikor, L., Al-Khalili, A., Danared, H., et al. 1999, A\&A, 344, 1027

Wakelam, V., Herbst, E., \& Selsis, F. 2006, A\&A, 451, 551

Wakelam, V., Loison, J.-C., Herbst, E., et al. 2009, A\&A, 495, 513

Wakelam, V., Smith, I. W. M., Herbst, E., et al. 2010a, Space Sci. Rev., 156, 13

Wakelam, V., Herbst, E., Le Bourlot, J., et al. 2010b, A\&A, 517, A21

Wakelam, V., Herbst, E., Loison, J.-C., et al. 2012, ApJS, 199, 21

Walmsley, C. M., Flower, D. R., \& Pineau des Forêts, G. 2004, A\&A, 418, 1035

Walsh, C., Harada, N., Herbst, E., \& Millar, T. J. 2009, ApJ, 700, 752

Whittet, D. C. B., Gerakines, P. A., Tielens, A. G. G. M., et al. 1998, ApJ, 498, L159

Whyte, A., \& Phillips, L. 1983, Chem. Phys. Lett., 98, 590

Wilson, P. F., Freeman, C. G., \& McEwan, M. J. 1993, Int. J. Mass Spectrom. Ion Proc., 128, 83

Wlodek, S., Bohme, D. K., \& Herbst, E. 1988, MNRAS, 235, 493

Woodall, J., Agúndez, M., Markwick-Kemper, A. J., \& Millar, T. J. 2007, A\&A, 466, 1197

Woon, D. E., \& Herbst, E. 1996, ApJ, 465, 795

Woon, D. E., \& Herbst, E. 2009, ApJS, 185, 273

Xu, Z.-F., Li, S.-M., Yu, Y.-X., Li, Z.-S., \& Sun, C.-C. 1999, J. Phys. Chem. A, 103,4910

Yamamoto, T., Nakagawa, N., \& Fukui, Y. 1983, A\&A, 122, 171

Yang, Z., Eichelberger, B., Carpenter, M. Y., et al. 2010, ApJ, 723, 1325

Yang, Z., Cole, C. A., Martinez, Jr., O., et al. 2011, ApJ, 739, 19

Zachariah, M. R., \& Tsang, W. 1995, J. Phys. Chem., 99, 5308

Zhang, F., Kim, S., Kaiser, R. I., \& Mebel, A. M. 2009, J. Phys. Chem. A, 113, 1210

Zhaunerchyk, V., Hellberg, F., Ehlerding, A., et al. 2005, Mol. Phys., 103, 2735 